\title{
Novas evidências empíricas sobre a dinâmica trimestral do consumo agregado das famílias brasileiras no período 1995-2009 *
}

\author{
Bernardo Patta Schettini; Cláudio Hamilton Matos dos Santos; \\ Cláudio Roberto Amitrano; Gabriel Coelho Squeff; \\ Márcio Bruno Ribeiro; Raphael Rocha Gouvêa; Rodrigo Octávio Orair; \\ Thiago Sevilhano Martinez ${ }^{* *}$
}

\begin{abstract}
Resumo
Este trabalho apresenta especificações econométricas inéditas para o consumo agregado das famílias brasileiras em níveis trimestrais, no período 1995-2009. Argumenta-se, em particular, que a utilização de aproximações trimestrais da renda disponível do setor privado (a preços de 1995 encadeados), do crédito disponibilizado às famílias brasileiras (em \% do PIB) e (de uma proxy) da taxa de juros real da economia como variáveis explicativas da dinâmica trimestral do consumo agregado dessas famílias gera modelos com elevado grau de ajuste "dentro da amostra" e "fora da amostra". Tais modelos sugerem, ainda, uma elasticidade-renda (privada, excluindo rendas líquidas de propriedade) próxima de 0,4 e semielasticidades-crédito e taxa de juros da ordem de $2 \%$ e $-2 \%$ para o consumo agregado das famílias brasileiras.
\end{abstract}

Palavras-chave: Consumo trimestral das famílias brasileiras; Renda disponível do setor privado; Cointegração com quebras estruturais; Modelos de espaço-estado; Modelos de alternância de regimes markovianos.

\begin{abstract}
New empirical evidence on the quarterly dynamics of Brazilian aggregate household consumption from 1995 to 2009

This paper presents new econometric specifications for the quarterly behavior of aggregate consumption of Brazilian households from 1995 to 2009. It is argued, in particular, that the use of quarterly measures of both private disposable income (in chained 1995 prices), the credit granted to households (as a \% of GDP) and a proxy for real interest rates as explanatory variables for the level of quarterly household consumption lead to well adjusted models "within the sample" with good "out of sample" performance. Moreover, the models presented in this paper point to values of the (approximated) private income elasticity around 0.4 and credit and interest (semi) elasticities of household consumption around $2 \%$ and $-2 \%$, respectively.
\end{abstract}

Keywords: Quarterly aggregate consumption of Brazilian households; private disposable income; cointegration models with structural breaks; state-space models; markov-switching models.

JEL E21, E27, C22, C52, C82.

* Trabalho recebido em 22 de julho de 2010 e aprovado em 6 de setembro de 2011.

*** Técnicos de Planejamento e Pesquisa do Instituto de Pesquisa Econômica Aplicada (IPEA), Brasília, DF, Brasil. E-mails: bernardo.schettini@ipea.gov.br; claudio.santos@ipea.gov.br; claudio.amitrano@ipea.gov.br; gabriel.squeff@ipea.gov.br; marcio.ribeiro@ipea.gov.br; raphael.gouvea@ipea.gov.br; rodrigo.orair@ipea.gov.br; thiago.martinez@ipea.gov.br. 


\section{Introdução}

O consumo das famílias é de longe o componente mais importante do produto interno bruto (PIB) brasileiro - tendo variado em torno de $60 \%$ deste último na média do quinquênio 2004/2008 (e em torno de 63,6\% entre 1995 e 2003). Não surpreende, assim, que os esforços anticíclicos da política econômica em 2009 tenham-se dirigido, em grande medida, à sustentação do consumo das famílias brasileiras $^{1}$.

A efetividade precisa das (várias) medidas anticíclicas adotadas pelo governo entre o quarto trimestre de 2008 e o terceiro trimestre de 2009 é - e provavelmente continuará sendo por bastante tempo - objeto de controvérsia entre os economistas. Este trabalho visa a oferecer uma contribuição para o referido debate, apresentando novas especificações econométricas para a dinâmica trimestral do (índice de volume do) consumo agregado das famílias brasileiras no período 1995/2009.

Os modelos apresentados no artigo têm várias características pouco usuais na literatura. Primeiro, tais modelos utilizam como variável explicativa uma proxy trimestral da renda disponível do setor privado construída a partir de estimativas trimestrais da carga tributária bruta, das transferências públicas de assistência e previdência social e subsídios produzidas pela Coordenação de Finanças Públicas do Instituto de Pesquisa Econômica Aplicada (IPEA) ${ }^{2}$. A rationale da referida proxy é apresentada na primeira seção deste trabalho. Todos os dados utilizados nas citadas estimativas do texto encontram-se em um apêndice ao final do mesmo, a fim de garantir que os resultados possam ser replicados por outros pesquisadores.

Em segundo lugar, optou-se por deflacionar a proxy trimestral (e nominal) da renda disponível do setor privado pelo deflator trimestral implícito do consumo do Instituto Brasileiro de Geografia e Estatística (IBGE) - e não pelo Índice Nacional de Preços ao Consumidor Amplo (IPCA), como é comum na literatura. Os motivos de tal opção estão na segunda seção deste trabalho - que discute as peculiaridades do índice de volume trimestral do consumo das famílias divulgado pelo IBGE.

Em terceiro lugar, não se restringiu a simplesmente testar se a teoria $\mathrm{A}, \mathrm{B}$ ou C sobre a dinâmica trimestral do consumo das famílias brasileiras pode ou não ser rejeitada à luz dos dados - como frequentemente é o caso na (relativamente pequena, diga-se) literatura recente sobre o tema. Com efeito, o artigo tem por objetivo explícito sugerir equações para a dinâmica trimestral do consumo das famílias brasileiras que simultaneamente (i) expliquem, de modo convincente, "o passado" - ou seja, apresentem excelentes ajustes "dentro da amostra"; (ii) projetem tão bem quanto possível "o futuro próximo" - isto é, apresentem bons ajustes oito e quatro trimestres "fora da amostra" quando condicionadas aos valores "corretos" das

(1) Ver Cepal (2010, p. 12-14) para um resumo dos referidos esforços.

(2) Santos e Costa (2008) e Santos, Macedo e Silva e Ribeiro (2010) explicam em detalhe as metodologias utilizadas em cada caso. 
variáveis explicativas ${ }^{3}$. A terceira seção deste trabalho resenha a literatura brasileira recente sobre a dinâmica do consumo agregado das famílias brasileiras.

Finalmente, as especificações são obtidas por meio de múltiplas técnicas econométricas. Diante das óbvias incertezas existentes acerca do processo gerador dos dados em questão - e da multiplicidade de técnicas econométricas de séries temporais atualmente à disposição dos pesquisadores - optou-se por rodar múltiplos modelos econométricos não lineares - a saber, modelos de cointegração com quebras (e.g. Gregory; Hansen, 1996), modelos de alternância de regimes markovianos (e.g. Krolzig, 1997) e modelos de espaço-estado (e.g. Harvey, 1989). Sublinhase, assim, que as conclusões gerais reportadas são robustas à adoção de variadas técnicas econométricas. A não linearidade destas últimas reflete, por sua vez, o fato de que quebras estruturais e mudanças de regime são comuns nos dados brasileiros. A quarta seção do texto apresenta e discute nossas especificações econométricas propriamente ditas.

Antecipando nossas conclusões - resumidas na última seção - nota-se que os modelos apresentados sugerem que (i) acréscimos de $1 \%$ na renda disponível do setor privado (aproximada) parecem estar associados a acréscimos de cerca de $0,4 \%$ no consumo das famílias brasileiras; (ii) acréscimos de 1\% do PIB no volume de crédito disponibilizado às famílias brasileiras parecem estar associados a acréscimos de $1,5 \%$ a $2 \%$ no consumo destas últimas; (iii) acréscimos de um ponto percentual na taxa de juro real mensal parecem estar associados a reduções de $1,5 \%$ a $2 \%$ no consumo das famílias brasileiras. Ademais, o erro de projeção dos referidos modelos é inferior a $1 \%$ e $2 \%$ um e dois anos fora da amostra, respectivamente, quando sujeitos aos valores corretos das variáveis explicativas.

\section{Aproximações trimestrais para a renda disponível do setor privado}

Viu-se acima que uma característica definidora das especificações econométricas é o fato de utilizar-se uma proxy trimestral da renda disponível do setor privado como variável explicativa do consumo das famílias brasileiras - e não, por exemplo, o PIB ou o Produto Nacional Bruto (PNB). O propósito desta seção é explicar a rationale da referida proxy.

\subsection{Conceitos básicos}

A renda disponível do "setor privado" é dada pela renda "primária" gerada por esse último setor, acrescida das "rendas líquidas de propriedade" e das "transferências líquidas" recebidas pelo setor privado tanto das "administrações públicas" quanto do "resto do mundo". A conceituação precisa dos termos entre aspas não é trivial, de modo que explicações adicionais são necessárias.

(3) Note-se que o fato de o IBGE ter revisto de forma muito significativa a série histórica trimestral do índice de volume (e dos valores nominais) do consumo das famílias brasileiras em meados de 2007 faz com que as estimativas publicadas antes desta data sejam pouco confiáveis. 
Começando pelo próprio termo "setor privado", nota-se que o mesmo é definido nas contas nacionais como o agregado das famílias, firmas "financeiras" e "não financeiras" e "instituições sem fins lucrativos a serviço das famílias". Notese que o setor privado assim definido inclui as empresas e os bancos estatais ${ }^{4}$. Daí, aliás, o fato de as contas nacionais utilizarem o conceito de "administrações públicas" (i.e. as administrações diretas e indiretas da União, estados e municípios, excluindo empresas e bancos estatais) e não o conceito mais familiar de "setor público".

Em contrapartida, dados da Tabela 1 deixam claro que as famílias são responsáveis por cerca de $80 \%$ do total da "renda disponível do setor privado" - de modo que essa última variável pode ser vista como uma aproximação - grosseira, por certo - da "renda disponível das famílias".

Tabela 1

Divisão da renda disponível do setor privado por setor institucional no período 2000-2006

\begin{tabular}{c|c|c|c|c|c}
\hline & $\begin{array}{c}\text { Instituições sem } \\
\text { fins lucrativos }\end{array}$ & Familias & $\begin{array}{c}\text { Firmas não } \\
\text { financeiras }\end{array}$ & $\begin{array}{c}\text { Firmas } \\
\text { financeiras }\end{array}$ & Total \\
\hline 2000 & 17967 & 792116 & 23292 & 127020 & 960395 \\
\hline 2001 & 19458 & 863076 & 38647 & 135642 & 1056823 \\
\hline 2002 & 22705 & 955618 & 76119 & 131405 & 1185847 \\
\hline 2003 & 24360 & 1096537 & 59748 & 192156 & 1372801 \\
\hline 2004 & 27896 & 1205344 & 55566 & 244099 & 1532905 \\
\hline 2005 & 32103 & 1327551 & 80023 & 239445 & 1679122 \\
\hline 2006 & 35851 & 1467153 & 120508 & 272413 & 1895925 \\
\hline
\end{tabular}

Fonte: IBGE (2009). Contas Econômicas Integradas, Referência 2000.

Passando agora ao conceito de "rendas líquidas de propriedade" (RLP) recebidas pelo setor privado, observa-se que o mesmo é dado pela soma dos valores de todos os juros, dividendos e "rendas da terra" e afins recebidos pelo setor privado das administrações públicas e do resto do mundo menos a soma dos valores de todos os juros, dividendos e "rendas da terra" e afins pagos pelo setor privado às administrações públicas e ao resto do mundo ${ }^{5,6}$. Somando-se as RLPs

(4) A Petrobrás, por exemplo, é classificada como uma "firma não financeira", enquanto que o Banco do Brasil (e mesmo o Banco Central) é classificado como "firma financeira" nas contas nacionais brasileiras.

(5) Note-se que quando, por exemplo, uma família paga juros a um banco nada é acrescentado às "rendas líquidas de propriedade" (RLPs) do setor privado uma vez que tanto a família quanto o banco fazem parte do setor privado (e o pagamento da primeira é compensado pelo recebimento do segundo). Apenas transações das administrações públicas e do resto do mundo com o setor privado é que afetam as RLPs desse último.

(6) A metodologia oficial das contas nacionais (IBGE, 2009, p.39) define "rendas de propriedade" como "rendimentos a receber pelo proprietário de um ativo financeiro ou de um ativo corpóreo não produzido (terrenos e ativos do subsolo), em troca da colocação de fundos ou da colocação do ativo corpóreo não produzido à disposição de outra unidade institucional." Note-se que aluguéis não entram nessa definição, tendo em vista que casas, apartamentos, prédios, escritórios etc são "ativos corpóreos produzidos". Os aluguéis entram, assim, no cálculo do excedente operacional e rendimento bruto dos setores institucionais e não nas rendas líquidas de propriedade dos mesmos. 
às rendas efetivamente "geradas" pelo setor privado (i.e. os salários e os lucros antes de tributos diretos e contribuições sociais - ou, no jargão, as remunerações dos empregados nacionais e o "excedente operacional e rendimento misto bruto" do setor privado, ambos a preços básicos) tem-se a chamada "renda primária bruta" do setor privado. Os valores dos componentes desta última variável no período 2000 2006 estão reportados na Tabela 3.

A "renda disponível bruta do setor privado" nada mais é do que a "renda primária do setor privado" (ver Tabela 3) menos as "transferências líquidas" de recursos do setor privado para as administrações públicas (principalmente) e para o resto do mundo. Tais transferências são basicamente de quatro tipos, a saber, (i) os tributos diretos pagos pelo setor privado às administrações públicas Imposto de Renda (IR), Imposto sobre a Propriedade de Veículos Automotores (IPVA), Imposto sobre a Propriedade Predial e Territorial Urbana (IPTU); (ii) as contribuições previdenciárias pagas pelo setor privado às administrações públicas (responsáveis pela administração dos regimes públicos de previdência social); (iii) os benefícios sociais (na forma de aposentadorias e pensões e programas assistenciais) recebidos pelo setor privado das administrações públicas; (iv) demais "transferências correntes" (que incluem o pagamento de prêmios e indenizações por parte de seguradoras, acordos de cooperação internacional e etc). A evolução do tamanho e da composição precisos das transferências líquidas de recursos do setor privado às administrações públicas e ao resto do mundo no período 2000-2006 está reportada na Tabela 2. Além disso, a Tabela 3 mostra a evolução da composição precisa da "renda disponível do setor privado" no período 2000-2006.

Tabela 2

Evolução do tamanho e da composição das transferências líquidas do setor privado às administrações públicas e ao resto do mundo no Período 2000-2006

\begin{tabular}{c|c|c|c|c|c}
\hline Ano & $\begin{array}{c}\text { Impostos sobre a } \\
\text { Renda co } \\
\text { Patrimônio }\end{array}$ & $\begin{array}{c}\text { Contribuiçōes } \\
\text { Previdenciárias }\end{array}$ & Beneficios Sociais & $\begin{array}{c}\text { Outras } \\
\text { Transferèncias } \\
\text { Correntes }\end{array}$ & Total \\
\hline 2000 & 87434 & 116571 & -147124 & -580 & 56301 \\
\hline 2001 & 104361 & 133519 & -167004 & -17667 & 53209 \\
\hline 2002 & 130237 & 150639 & -199399 & 906 & 82383 \\
\hline 2003 & 147277 & 172379 & -237475 & -10870 & 95118 \\
\hline 2004 & 165818 & 199624 & -262605 & 4712 & 1357 \\
\hline 2005 & 202442 & 224550 & -296449 & -6770 & 130670 \\
\hline 2006 & 220867 & 251797 & -335224 & & 967 \\
\hline
\end{tabular}

Fonte: IBGE (2009). Contas Econômicas Integradas, Referência 2000. 
Tabela 3

Evolução do tamanho e da composição da renda primária e da renda disponível do setor privado no período 2000-2006 (em R\$ milhões nominais)

\begin{tabular}{|c|c|c|c|c|c|c|}
\hline Ano & $\begin{array}{l}\text { Remunerasio de } \\
\text { empregados } \\
\text { nacionais a preços } \\
\text { básicos (A) }\end{array}$ & $\begin{array}{l}\text { Excedente } \\
\text { operacional e } \\
\text { rendimento misto } \\
\text { brutos a prepos } \\
\text { básicos (B) }\end{array}$ & $\begin{array}{c}\text { Rendas } \\
\text { liquidas de } \\
\text { propriedade } \\
\text { (C) }\end{array}$ & $\begin{array}{l}\text { Renda Prīnária } \\
\text { do Setor Privado } \\
(\mathrm{D}-\mathrm{A}+\mathrm{B}+\mathrm{C})\end{array}$ & $\begin{array}{l}\text { Transferếncias } \\
\text { liquidas fcitas às } \\
\text { administraçòes } \\
\text { públicas e ao resto do } \\
\text { mundo }(\mathrm{E})\end{array}$ & $\begin{array}{c}\text { Renda } \\
\text { Disponivel do } \\
\text { Setor Privado } \\
\text { (F-D-E) }\end{array}$ \\
\hline 2000 & 477479 & 515535 & 23682 & 1016696 & 56301 & 960395 \\
\hline 2001 & 528608 & 557429 & 23995 & 1110032 & 53209 & 1056823 \\
\hline 2002 & 588802 & 645558 & 33870 & 1268230 & 82383 & 1185847 \\
\hline 2003 & 672205 & 752735 & 42978 & 1467918 & 95118 & 1372800 \\
\hline 2004 & 763765 & 848973 & 12134 & 1624872 & 91967 & 1532905 \\
\hline 2005 & 861418 & 922132 & 30787 & 1814377 & 135255 & 1679122 \\
\hline 2006 & 969780 & 1002201 & 54614 & 2026595 & 130670 & 1895925 \\
\hline
\end{tabular}

Fonte: IBGE (2009). Contas Econômicas Integradas, Referência 2000.

\subsection{Aproximações trimestrais da renda disponível do setor privado}

Infelizmente, não existem séries trimestrais oficiais da "renda disponível do setor privado". A presente seção visa a esclarecer o leitor sobre como se obtiveram aproximações trimestrais úteis - conquanto admitidamente imperfeitas - deste último conceito.

No início, notou-se que não há séries de alta frequência disponíveis aos componentes desagregados da "renda disponível do setor privado" (ver Tabela 3). Assim, as aproximações sugeridas no artigo são calculadas de modo indireto, a partir da identidade contábil entre o PIB e a soma das rendas disponíveis dos setores público e privado com a "renda líquida enviada ao exterior" e as transferências unilaterais (líquidas) recebidas por nacionais.

É usual designar-se a soma das rendas disponíveis das administrações públicas e do setor privado como a "renda nacional disponível" (RND). Tal variável é de cálculo simples (trata-se, por definição do PIB - Renda Líquida Enviada ao Exterior + Transferências Unilaterais Líquidas Recebidas do Exterior) e é publicada nas contas nacionais trimestrais ${ }^{7}$. De posse da RND, tudo de que precisamos para calcular a renda disponível do setor privado (RDSP) é saber o valor da renda disponível das administrações públicas (RDAP), uma vez que a RDSP é, por definição, igual à RND - RDAP. Felizmente, existem algumas séries de alta frequência para componentes importantes da RDAP que podem ser utilizadas na tentativa de aproximar indiretamente o valor da RDSP. Antes, entretanto, cumpre lembrar ao leitor os componentes precisos da RDAP (Tabelas 4 e 5).

(7) Desde 2007 (com a publicação das contas nacionais referência 2000), a série trimestral da RND publicada pelo IBGE começa no ano 2000. Valores desde 1995, no entanto, podem ser construídos (i) assumindo-se (como plausível) que os valores da Renda Líquida Enviada ao Exterior e das Transferências Unilaterais Líquidas publicados nas contas nacionais (trimestrais) ref. 1985 continuam corretos; (ii) subtraindo esses últimos valores dos novos valores (ref. 2000) divulgados para o PIB trimestral desde 1995. Tal procedimento foi adotado neste trabalho. 
Novas evidências empíricas sobre a dinâmica trimestral do consumo agregado...

Tabela 4

Evolução do tamanho e da composição da renda primária das administrações públicas no período 2000-2006 (em R \$ milhões nominais)

\begin{tabular}{c|c|c|c|c}
\hline Ano & $\begin{array}{c}\text { Impostos liquidos de } \\
\text { subsidios sobre produtos } \\
\text { c produção }\end{array}$ & $\begin{array}{c}\text { Excedente operacional } \\
\text { bruto a preços básicos }\end{array}$ & $\begin{array}{c}\text { Rendas liquidas } \\
\text { de propriedade }\end{array}$ & Total \\
\hline 2000 & 166970 & 19643 & -56416 & 130197 \\
\hline 2001 & 194735 & 21583 & -69718 & 146600 \\
\hline 2002 & 219996 & 23794 & -86134 & 157656 \\
\hline 2003 & 247440 & 27901 & -98453 & 176888 \\
\hline 2004 & 298.285 & 30971 & -71143 & 258145 \\
\hline 2005 & 330412 & 33769 & -92905 & 271276 \\
\hline 2006 & 362176 & 35716 & -113589 & 284303 \\
\hline
\end{tabular}

Fonte: Contas Econômicas Integradas, Referência 2000.

Tabela 5

Evolução do tamanho e da composição da renda disponível das administrações públicas no período 2000-2006 (em R \$ milhões nominais)

\begin{tabular}{|c|c|c|c|c|c|c|}
\hline Ano & $\begin{array}{l}\text { Renda Primária } \\
\text { Bruta das } \\
\text { Administraçōes } \\
\text { Públicas }\end{array}$ & $\begin{array}{c}\text { Impostos sobre a } \\
\text { Renda e o } \\
\text { Patrimônio }\end{array}$ & $\begin{array}{c}\text { Contribuições } \\
\text { Sociais }\end{array}$ & $\begin{array}{l}\text { Beneficios } \\
\text { de } \\
\text { Assistência e } \\
\text { Previdência }\end{array}$ & $\begin{array}{c}\text { Outras } \\
\text { transferências } \\
\text { correntes }\end{array}$ & Total \\
\hline 2000 & 130197 & 87434 & 116571 & -147124 & 2210 & 189288 \\
\hline 2001 & 146600 & 104361 & 133519 & -167004 & -13800 & 203676 \\
\hline 2002 & 157656 & 130237 & 150639 & -199399 & 8171 & 247304 \\
\hline 2003 & 176888 & 147277 & 172379 & -237475 & 21688 & 280757 \\
\hline 2004 & 258145 & 165818 & 199624 & -262605 & -1307 & 359675 \\
\hline 2005 & 271276 & 202442 & 224550 & -296449 & 13347 & 415166 \\
\hline 2006 & 284303 & 220867 & 251797 & -335224 & 2596 & 424339 \\
\hline
\end{tabular}

Fonte: Contas Econômicas Integradas, Referência 2000.

Para os nossos propósitos, é útil dividir os componentes da renda disponível das administrações públicas em quatro grupos, a saber: (i) carga tributária líquida (CTL), aproximada pela soma dos impostos sobre produtos, com os impostos sobre a renda e o patrimônio e as contribuições sociais menos os benefícios de assistência e previdência; (ii) as rendas líquidas de propriedade; (iii) excedente operacional bruto; (iv) outras transferências correntes recebidas (ver Tabela 6). O ponto de propor essa desagregação alternativa é que, em princípio, ao menos, há aproximações trimestrais razoáveis para a "carga tributária líquida" desde 1995 (ver Santos, Macedo e Silva e Ribeiro, 2010). Ademais, os pagamentos (líquidos) de juros pelas administrações públicas são, de longe, o item mais importante no cálculo das "rendas líquidas de propriedade" (RLPs) das administrações públicas, de modo que se poderia pensar em utilizar a soma das séries de "despesas líquidas com juros nominais" dos governos federal, estaduais e municipais produzidas pelo Banco Central do Brasil como proxy das RLPs públicas. Até onde se sabe, estimativas tanto para o excedente operacional bruto das administrações públicas como para as "outras transferências correntes recebidas" não estão disponíveis - mas, felizmente, o peso relativo de 
ambos os componentes no total da renda disponível das administrações públicas não é particularmente alto.

Tabela 6

Agregação alternativa dos componentes da renda disponível das administrações públicas no período 2000-2006 (em R \$ milhões nominais)

\begin{tabular}{c|c|c|c|c|c}
\hline Ano & $\begin{array}{c}\text { Proxy da "carga } \\
\text { tributária liquida" }\end{array}$ & $\begin{array}{c}\text { Rendas Liquidas } \\
\text { de Propriedade }\end{array}$ & $\begin{array}{c}\text { Excedente } \\
\text { Operacional Bruto }\end{array}$ & $\begin{array}{c}\text { Outras } \\
\text { transferências } \\
\text { Correntes }\end{array}$ & Total \\
\hline 2000 & 223,851 & $-56,416$ & 19,643 & 2,21 & 189,288 \\
\hline 2001 & 265,611 & $-69,718$ & 21,583 & $-13,8$ & 203,676 \\
\hline 2002 & 301,473 & $-86,134$ & 23,794 & 8,171 & 247,304 \\
\hline 2003 & 329,621 & $-98,453$ & 27,901 & 21,688 & 280,757 \\
\hline 2004 & 401,154 & $-71,143$ & 30,971 & $-1,307$ & 359,675 \\
\hline 2005 & 460,955 & $-92,905$ & 33,769 & 13,347 & 415,166 \\
\hline 2006 & 499,616 & $-113,589$ & 35,716 & 2,596 & 424,339 \\
\hline
\end{tabular}

Fonte: Contas Econômicas Integradas, Referência 2000.

Recapitulando o argumento feito até agora: (i) a carga tributária líquida e as "rendas líquidas de propriedade" são de longe os componentes mais importantes da renda disponível das administrações públicas (RDAP); (ii) assim, a chave para conseguir boas aproximações trimestrais para essa última variável é conseguir boas aproximações das duas primeiras; (iii) como visto anteriormente, de posse de aproximações trimestrais razoáveis da RDAP, podem ser utilizadas as séries trimestrais da renda nacional disponível e do PIB publicadas pelo IBGE para calcular estimativas trimestrais razoáveis da renda disponível privada (RDP), que é a variável de interesse no momento.

Argumenta-se no restante dessa seção sobre que as aproximações trimestrais possíveis da "carga tributária líquida" parecem razoáveis, embora o mesmo não possa ser dito das aproximações trimestrais dos juros pagos pelas administrações públicas. Segue, então, que as melhores estimativas da renda disponível do setor privado a serem construídas no momento são aquelas calculadas subtraindo-se as estimativas trimestrais da carga tributária líquida, produzidas pela Coordenação de Finanças Públicas do IPEA da série de renda nacional disponível publicada nas contas nacionais do IBGE.

Nota-se que o valor efetivamente publicado pelo IBGE para a carga tributária líquida é sempre inferior ao reportado na Tabela 6. São dois os motivos básicos para isso. Primeiro, e mais importante, o valor das "contribuições sociais" reportado na Tabela 5 inclui as chamadas "contribuições sociais imputadas" - que não entram no cálculo da carga tributária bruta ou líquida. O segundo motivo é que o IBGE curiosamente inclui os "impostos sobre o capital" entre as "outras transferências correntes", ou seja, a proxy da carga tributária líquida reportada na Tabela 6 deixa de levar estes últimos impostos em consideração como receita das administrações 
públicas. A Tabela 7 deixa claro que o valor da CTL efetivamente divulgado pelo IBGE é bastante compatível com os valores apresentados na Tabela 6 quando se controla por essas duas diferenças conceituais.

Tabela 7

O quão boa é a "proxy" da carga tributária líquida da tabela 6 ?

(em R \$ bilhões nominais)

\begin{tabular}{c|c|c|c|c|c}
\hline Ano & $\begin{array}{c}\text { Proxy da CTL da } \\
\text { tabela 6 }\end{array}$ & $\begin{array}{c}(-) \text { CTL } \\
\text { publicada pelo } \\
\text { IBGE }\end{array}$ & $\begin{array}{c}(-) \text { Contribuições } \\
\text { Sociais } \\
\text { "Imputadas" }\end{array}$ & $\begin{array}{c}(+) \text { Impostos } \\
\text { sobre o capital }\end{array}$ & $\begin{array}{c}\text { (=) Discrepância } \\
\text { não explicada }\end{array}$ \\
\hline 2000 & 223,85 & 200,12 & 21,73 & 1,67 & 3,66 \\
\hline 2001 & 265,61 & 237,44 & 25,74 & 1,69 & 4,12 \\
\hline 2002 & 301,47 & 270,30 & 28,01 & 2,16 & 5,32 \\
\hline 2003 & 329,62 & 294,46 & 31,05 & 2,69 & 6,80 \\
\hline 2004 & 401,15 & 362,72 & 31,96 & 2,73 & 9,20 \\
\hline 2005 & 460,96 & 414,46 & 38,44 & 3,25 & 11,29 \\
\hline 2006 & 499,62 & 456,45 & 34,99 & 3,85 & 12,03 \\
\hline
\end{tabular}

Fonte: IBGE (2009). Contas Econômicas Integradas e Tabelas Sinóticas 19 e 20

Por sua vez, a utilização dos dados das despesas das administrações públicas (União, estados e municípios, excluindo estatais e o Banco Central) com juros publicados pelo Banco Central para aproximar os dados efetivamente publicados pelo IBGE não parece sensata - em vista das enormes discrepâncias (de vários pontos percentuais do PIB) entre os valores anualizados da série do Banco Central e os valores divulgados pelo IBGE nas contas nacionais anuais. Conquanto a discussão das diferenças entre metodologias utilizadas pelas duas instituições esteja fora do escopo deste trabalho, cumpre frisar aqui que tais diferenças são sérias a ponto de inviabilizar completamente a utilização de uma série para aproximar a outra. Desse modo, para fins deste trabalho, a renda disponível do setor privado será igual à renda nacional disponível menos a carga tributária líquida.

\section{Consumo nas contas nacionais: valores nominais, volumes e deflator implícito}

Os dados trimestrais do consumo final das famílias são divulgados pelo IBGE tanto como um índice de volume quanto em valores correntes. Esse fato gera alguns questionamentos naturais. Qual o índice de preços mais apropriado para deflacionar as séries de rendimentos em valores nominais? É mais apropriado utilizar a série do consumo em volume ou valores correntes deflacionados?

Para responder a tais questionamentos é necessário explicitar alguns procedimentos que o IBGE utiliza na estimação do consumo das famílias nas contas nacionais anuais e trimestrais. No Novo Sistema de Contas Nacionais (NSCN divulgado em março de 2007), o IBGE utiliza um vetor de consumo das famílias obtido a partir das informações da POF 2002/2003. Esse vetor de consumo mostra a proporção da renda que as famílias gastam com cada um dos 110 produtos do 
NSCN, sendo que as famílias são divididas em distintos perfis de consumo conforme suas faixas de renda e região de moradia. Em seguida, o IBGE utiliza o vetor de consumo e as informações sobre os rendimentos (anualizados) da PNAD para obter o montante anual das despesas de consumo das famílias de cada produto nas distintas regiões do país ${ }^{8}$. O agregado de tais despesas corresponde à estimativa inicial dos valores nominais do consumo final das famílias nas contas nacionais anuais.

Para chegar a uma estimativa também inicial do volume de consumo, o IBGE deflaciona os respectivos valores nominais com índices de preços específicos para cada um dos 110 produtos do NSCN e formados pela composição dos subitens do IPCA ${ }^{9}$. Por fim, o IBGE submete as estimativas iniciais dos valores e volumes consumidos por produto a análises de consistência feitas por seus "setorialistas" e ao processo de equilíbrio de recursos e usos (ou oferta e demanda). As estimativas finais do consumo, portanto, podem ser ajustadas e diferidas dos valores iniciais.

É possível, portanto, obter um deflator anual implícito do consumo que corresponde à razão entre o valor nominal e o volume de consumo final das famílias. Esse deflator implícito do consumo nas contas nacionais anuais irá diferir do IPCA, mesmo que seja derivado dos subitens do IPCA. Dentre as principais razões para as diferenças, têm-se: i) as estruturas de ponderação no índice agregado são distintas no que diz respeito à composição dos produtos (ou subitens do IPCA) e o peso das regiões; ii) as ponderações dos produtos no deflator implícito das contas nacionais são atualizadas a cada ano de acordo com as novas estimativas das despesas de consumo das famílias (índice de preços com ponderações finais do tipo Paasche) enquanto no IPCA a estrutura está fixa, atualizando-se apenas após a realização de uma nova POF (ponderações inicias do tipo Laspeyres); iii) os ajustes realizados pelo IBGE para conferir consistência aos dados e equilíbrio de recursos e usos podem modificar tanto os valores nominais quanto os volumes do consumo final das famílias e, assim, alterar o deflator implícito do consumo.

A Tabela 8 compara os valores do deflator anual implícito do consumo com os valores do IPCA. Observa-se que desde o ano 2000 (ano base do NSCN) os dois índices de preços passaram a apresentar valores não muito distintos e suas diferenças alternam valores negativos e positivos, sem apresentar um viés sistemático ${ }^{10}$. Em princípio, ambos seriam adequados para deflacionar as séries de rendimentos em valores nominais e refletir as mudanças no poder de compra das famílias. A decisão

(8) As despesas com produtos da construção são obtidas pelos mesmos procedimentos, mas consideradas como formação bruta de capital fixo (e não como consumo das famílias). Para alguns produtos, são utilizadas outras fontes de informação, como as dos fabricantes e do comércio varejista para automóveis e eletrodomésticos.

(9) Para refletir os preços médios do ano, utiliza-se a razão entre a média do índice de preços acumulado no ano e a média acumulada no ano anterior. Os índices são específicos para cada produto do NSCN e formados pela composição dos subitens do IPCA.

(10) No período de 1995 a 1999, houve apenas retropolação no NSCN referência 2000, mas sem a implementação de mudanças como a integração com as bases anuais do IBGE. 
sobre quais dos dois índices é o mais adequado requer a análise adicional dos procedimentos de estimação do consumo nas contas nacionais trimestrais.

Tabela 8

Comparação das variações anuais do IPCA e do deflator implícito do consumo das famílias no período 1996-2007

\begin{tabular}{c|c|c|c}
\hline Ano & $\begin{array}{c}\text { Deflator anual implicito do } \\
\text { consumo (A) }\end{array}$ & $\begin{array}{c}\text { Razão entre a média do IPCA } \\
\text { acumulada no ano em relação } \\
\text { ao ano anterior (B) }\end{array}$ & $\begin{array}{c}\text { Discrepância (\%) } \\
(\mathrm{C})=(\mathrm{A})(\mathrm{B})-1\end{array}$ \\
\hline 1995 & - & - & - \\
\hline 1996 & 1,1995 & 1,1576 & 3,6 \\
1997 & 1,0836 & 1,0693 & 1,3 \\
\hline 1998 & 1,0415 & 1,0320 & 0,9 \\
\hline 1999 & 1,0901 & 1,0486 & 4,0 \\
\hline 2000 & 1,0582 & 1,0704 & $-1,1$ \\
\hline 2001 & 1,0816 & 1,0684 & 1,2 \\
\hline 2002 & 1,0827 & 1,0845 & $-0,2$ \\
\hline 2003 & 1,1633 & 1,1471 & 1,4 \\
\hline 2004 & 1,0619 & 1,0660 & $-0,4$ \\
\hline 2005 & 1,0675 & 1,0687 & $-0,1$ \\
\hline 2006 & 1,0495 & 1,0418 & 0,7 \\
\hline 2007 & 1,0518 & 1,0364 & 1,5 \\
\hline
\end{tabular}

Fonte: Cálculos dos autores.

Mesmo que integrados, os procedimentos das contas nacionais anuais e trimestrais são distintos. Nas contas trimestrais, o IBGE assume a hipótese de que a despesa de consumo das famílias em volume cresce proporcionalmente à oferta a preços básicos (valor bruto de produção mais importações líquida das exportações). A estimativa inicial do índice de volume trimestral das despesas de consumo das famílias nada mais é do que a razão entre a oferta líquida do trimestre corrente (a preços médios trimestrais do ano anterior) e a oferta líquida média trimestral do ano anterior. $\mathrm{O}$ índice de preço para o consumo das famílias nas contas trimestrais é o próprio IPCA. O índice de valor nominal do consumo trimestral das famílias corresponde ao produto do índice de volume e do índice de preços.

O valor nominal e o volume do consumo trimestral das famílias também estão sujeitos aos testes de consistência e ajustamentos realizados pelos setorialistas do IBGE. Ademais, as contas nacionais trimestrais são indicadores conjunturais e submetidos a novos ajustes sempre que um novo dado de referência das contas nacionais anuais é disponibilizado (o chamado benchmark) ${ }^{11}$. Tais ajustamentos também fazem com que o deflator implícito do consumo das contas trimestrais (razão entre o valor nominal e o volume de consumo do trimestre) modifique-se em

(11) Desde 1995, o IBGE integrou o sistema de contas trimestrais com as contas nacionais anuais. Em geral, as contas anuais são disponibilizadas com uma defasagem de 2 anos e as contas trimestrais de até 3 meses, por isso sempre que é disponibilizado um novo dado anual de referência, faz-se necessário o ajuste dos indicadores conjunturais mais recentes das contas trimestrais. 
relação ao IPCA que lhe serviu de referência. Os mesmos ajustes fazem, no entanto, com que o deflator trimestral implícito do consumo tenha correspondência com o deflator implícito das contas nacionais anuais.

Em suma, o deflator implícito do consumo nas contas nacionais, mesmo que derivado do IPCA (ou dos subitens do IPCA), apresenta divergências em função dos ajustes a que está sujeito e das diferentes estruturas dos dois índices de preços. Ambos, porém, refletem as mudanças nos preços dos produtos consumidos pelas famílias. Temos, assim, duas alternativas para obter séries em valores constantes (ou em volume): i) utilizar os dados do volume de consumo final das famílias nas contas nacionais e deflacionar as séries de rendimentos pelo deflator trimestral implícito do consumo ou ii) utilizar os valores nominais do consumo final das famílias e dos rendimentos e deflacioná-los pela média do IPCA acumulado no trimestre.

Neste trabalho, optou-se pela primeira alternativa. Ora, o volume de consumo é o que serve de referência nas contas nacionais trimestrais, multiplicado pelo índice de preços derivado do IPCA para obtenção da estimativa inicial do valor corrente do consumo final das famílias. Grosso modo, a segunda alternativa significa o mesmo que tomar o volume do consumo das famílias, multiplicá-lo por um índice de preços derivado do IPCA (mas não exatamente igual) para obter os valores correntes e deflacioná-lo pelo IPCA, obtendo-se novamente o volume de consumo. Tal procedimento não apenas é redundante como também faz com que o volume de consumo resultante após o deflacionamento afaste-se do dado original. Daí, a opção pela primeira alternativa: utilizar os dados do volume de consumo final das famílias e deflacionar as séries de rendimentos pelo deflator trimestral implícito do consumo, ambos encadeados a preços de 1995.

\section{Breve resenha da literatura recente sobre a dinâmica do consumo das famílias no Brasil}

A literatura brasileira recente sobre o consumo agregado tem-se concentrado em testar a aderência dos dados nacionais a especificações teóricas alternativas. As exceções são as funções consumo agregadas estimadas como parte de modelos macroeconométricos gerais sobre a economia brasileira. Nessa seção, são apresentados brevemente os principais estudos que integram as duas vertentes.

A maior parte dos estudos sobre consumo no Brasil (Reis et al., 1998; Issler e Rocha, 2000; Gomes, 2004; Gomes et al., 2005; Paz, 2006 ; Gomes, 2010 e Abe, 2010) testa a validade da Hipótese do Ciclo de Vida (HCV)-Teoria da Renda Permanente (TRP) contra especificações alternativas, em especial a teoria keynesiana, segundo a qual o consumo tem uma relação direta com a renda corrente. A versão moderna da HCV-TRP, formalizada por Hall (1978) e Flavin (1981), estabelece a decisão de consumo como um problema de maximização intertemporal com agentes dotados de expectativas racionais. Os agentes não levam em conta a renda corrente, mas sim, sua renda permanente, poupando ou tomando crédito de acordo com a taxa de juros 
para suavizar o consumo intertemporalmente. Assim, supondo dadas as preferências intertemporais dos agentes e que choques inesperados são aleatórios, apenas a taxa de juros real ex ante deve afetar o consumo corrente, pois oscilações na renda ou são vistas como temporárias ou já estavam previstas no cálculo da renda permanente ${ }^{12}$.

O texto de Reis et al. (1998) testa duas proposições, isto é, se há poupança precaucional no Brasil, utilizando dados trimestrais de 1975 a 1994 e a validade da $H C V$-TRP contra a hipótese de consumo keynesiano, com os mesmos dados trimestrais e também com dados anuais de 1947 a 1994. Considerando que o consumidor típico segue o modelo de Hall (1978), foram encontradas evidências fortes a favor da existência de poupança precaucional devido à incerteza macroeconômica, medida por um parâmetro relacionado à variância do consumo esperado. Os autores, contudo, estimam também que $80 \%$ das variações no consumo brasileiro são explicadas conforme o modelo keynesiano e não pela $H C V$-TRP. Esse resultado é obtido, utilizando-se o modelo híbrido de Campbell e Mankiw (1989) que consiste em estimar a proporção $(\lambda)$ de consumidores keynesianos, os quais consomem de acordo com a renda corrente, e a proporção $(1-\lambda)$ de consumidores que seguem a $H C V$-TRP. Observam ainda que a taxa de juros real não é significativa como determinante do consumo, o que implica em baixo poder explicativo da $\mathrm{HCV}$ TRP para explicar o consumo no país.

O artigo de Gomes (2004) testa uma explicação alternativa para a não aplicabilidade da $H C V$-TRP, qual seja, a hipótese de formação de hábito. Considerando que o parâmetro de desconto e a taxa de juros sejam iguais, o consumo deveria seguir um passeio aleatório pela $H C V-T R P$, o que implicaria ser o consumo dado por uma tendência estocástica. Ao observar que a série de consumo anual de 1947 a 1999 no Brasil tem um componente cíclico além da tendência estocástica, o autor trabalha com a hipótese de formação de hábito e introduz um termo de inércia na função utilidade do consumido. A hipótese de formação de hábito, contudo, é rejeitada no confronto com a hipótese alternativa de consumo conforme a renda corrente, a regra keynesiana.

Em Gomes et al. (2005), é testada para o Brasil a hipótese de separabilidade do consumo de bens duráveis e não duráveis. O uso da série agregada de consumo para testar a $H C V$-TRP só é válido se os gastos com bens duráveis e não duráveis puderem ser modelados separadamente na função utilidade, sem a inclusão de um termo cruzado. O teste não rejeita a hipótese, validando estudos com o consumo agregado. Ademais, o artigo também testa o modelo híbrido de Campbell e Mankiw (1989) para dados anuais de 1970 a 1998, repetindo o resultado favorável à hipótese keynesiana.

(12) Hall (1978) supõe adicionalmente que a taxa de juros é igual ao parâmetro de desconto intertemporal da utilidade marginal do consumidor, de maneira que ambos cancelam-se e o consumo segue um passeio aleatório. Se essa hipótese é relaxada, a taxa de juros real ex ante deve afetar o consumo, o que é testado empiricamente em outros artigos como Campbell e Mankiw (1989). 
Paz (2006) e Gomes (2010) também encontram um efeito não significativo da taxa de juros sobre o consumo, usando respectivamente dados trimestrais de 1991 a 2004 e anuais de 1970 a 2005. Testam para o Brasil uma alternativa para explicar a rejeição da $H C V-T R P$, a hipótese de miopia no consumo de Shea (1995) ${ }^{13}$. O agente que consome seguindo estritamente sua renda corrente é interpretado por Campbell e Mankiw (1989) como um caso de restrição de crédito. Para Shea (1995), todavia, esse comportamento na verdade caracteriza um agente míope, pois, sob restrição de crédito, um agente racional iria poupar mais em épocas de crescimento da renda para evitar reduções no consumo em fases de queda na renda. Assim, a resposta do consumo à renda seria maior para suas elevações do que para reduções, o que pode ser testado separando os efeitos das variações positivas e negativas da renda com o uso de variáveis binárias multiplicativas. Ambos os artigos encontraram resultados contraditórios nos testes, não conseguindo concluir se a rejeição da $H C V-T R P$ é devida à miopia ou à restrição de crédito.

Já, o trabalho de Abe (2010) discute a hipótese de suavização do consumo no Brasil em diferentes recortes temporais em função da presença de quebras estruturais, com dados trimestrais de 1991 ao segundo trimestre de 2009. O autor observou redução substancial do efeito da renda corrente sobre o consumo no período após uma quebra no segundo trimestre de 2004, sugerindo uma proximidade maior com a $H C V-T R P$, apesar da quantidade pequena de observações no período.

Por fim, alguns trabalhos testam comparativamente a adequação de especificações teóricas a diferentes países da América do Sul, incluindo o Brasil. Gomes e Paz (2004), com dados anuais de 1951 a 2000, rejeitam para sete países a validade da $H C V-T R P$, estimando no modelo híbrido um $\lambda$ médio de 0,61 para o Brasil. No teste do modelo híbrido, Paz e Gomes (2008) rejeitam a $H C V$-TRP para três países e não rejeitam para a Venezuela com dados de 1950 a 2000, enquanto no teste de Shea (1995), não conseguem discriminar entre miopia e restrição à liquidez para o Brasil. Gomes e Franchini (2009), com 10 países sul-americanos, testam a ordem de integração da propensão média a consumir (PMC), conduzindo testes individuais e em painel, com e sem quebras estruturais e obtêm que apenas no teste em painel com quebra a PMC é um processo estacionário - evidências indicativas de que não é possível rejeitar a $H C V$-TRP, bem como o modelo de hábito.

É, portanto, um resultado comum da grande maioria dos trabalhos empíricos preocupados em testar a validade de teorias do consumo cuja renda corrente para o Brasil é o principal determinante do consumo, embora não esteja claro se devido à ocorrência de miopia ou por restrição de crédito.

Outra linha de investigação são estimações da função consumo no âmbito de modelos macroeconométricos. Tais trabalhos diferem dos anteriores pela preocupação não em testar teorias, mas em obter o melhor ajuste possível aos dados disponíveis.

(13) Para esse teste, Gomes (2010) utiliza dados anuais de 1947 a 2005. 
Dentre os modelos publicados na última década, o modelo de Reis et al. (1999), é o de maior escala. Com características keynesianas e tendo como objetivo possibilitar projeções e simulações de política econômica, o modelo tem 131 variáveis endógenas (32 estimadas econometricamente), divididas em seis blocos (Demanda e Oferta Agregadas, Preços e Emprego, Setores Monetário, Público e Externo). A especificação da função consumo utiliza como variáveis explicativas o total de crédito ao setor privado, a taxa real de juros e a renda disponível do setor privado, além de um mecanismo de correção de erro que supõe a vigência de uma relação de longo prazo de 1:1 entre consumo e renda, de modo que suas trajetórias futuras não possam afastar-se indefinidamente. A equação foi estimada por variáveis instrumentais, devido a problemas de endogeneidade, o que propiciou estimativas consistentes. Dois resultados chamam a atenção: o baixo valor encontrado $(0,4)$ para o coeficiente estimado para renda; o efeito baixo e secundário da taxa real de juros na determinação do consumo, cabendo ao crédito um papel mais proeminente.

Outro estudo importante é o de Muinhos e Alves (2003) que desenvolvem um modelo de "médio porte" com dados das Contas Nacionais Trimestrais do IBGE. O modelo é dividido em quatro blocos (demanda, oferta, setor externo e monetário-fiscal), totalizando mais de 30 equações dentre estimações econométricas e identidades. A estimação da função consumo foi feita por mínimos quadrados ordinários a partir de uma equação do logaritmo da razão consumo-renda disponível, modelada em nível, contra o produto potencial ${ }^{16}$ e a taxa real de juros de curto prazo. Os autores não teceram comentários sobre a função consumo seja com relação à validade das diversas teorias, seja sobre sua capacidade de projeção dentro ou fora da amostra.

Por fim, Cavalcanti et al. (2002) $)^{17}$ apresentam uma versão trimestral reduzida do modelo de Reis et al. (1999). A principal diferença é que a variação do consumo depende apenas da variação da renda disponível e da taxa de juros real. A função consumo estimada indicou um coeficiente de 0,56 para a renda e a predominância sobre o consumo do efeito da renda disponível vis-à-vis a taxa de juros.

\section{Dados e especificação econométricas propriamente ditos}

Começando pela descrição dos dados, nota-se que as especificações econométricas apresentadas neste trabalho são baseadas nas seguintes séries:

(16) O produto potencial foi obtido a partir de estimativas dos próprios autores de uma função de produção do tipo Cobb-Douglas no bloco de oferta do modelo. Os autores informaram que também testaram a renda corrente, mas a mesma mostrou-se inadequada como regressor, provavelmente devido a problemas de multicolinearidade com o produto potencial.

(17) Esse texto também apresenta, sucintamente, a estrutura e o modelo desenvolvido em Reis et al. (1999). Ademais, no que concerne às estimativas de longo prazo com bases trimestrais, apresenta os mesmos resultados reportados em Cavalcanti (2000), mas com maior grau de detalhamento. 
(i) Consumo trimestral das famílias brasileiras, valores encadeados a preços de 1995. Em logaritmos neperianos, com e sem ajuste sazonal ${ }^{16}$.

(ii) PIB trimestral, valores encadeados a preços de 1995. Em logaritmos neperianos, com e sem ajuste sazonal.

(iii) Proxy da renda disponível do setor privado brasileiro trimestral medida a preços (encadeados) de 1995 a partir do deflator implícito do consumo. Em logaritmos neperianos, com e sem ajuste sazonal.

(iv) Operações de Crédito do Sistema Financeiro (risco total) a pessoas físicas em \% do PIB (média mensal dentro em cada trimestre).

(v) Proxy para a taxa de juros real ao mês (média mensal dentro de cada trimestre).

Gráfico 1

Comportamento das variáveis utilizadas neste texto no período 1995-2009
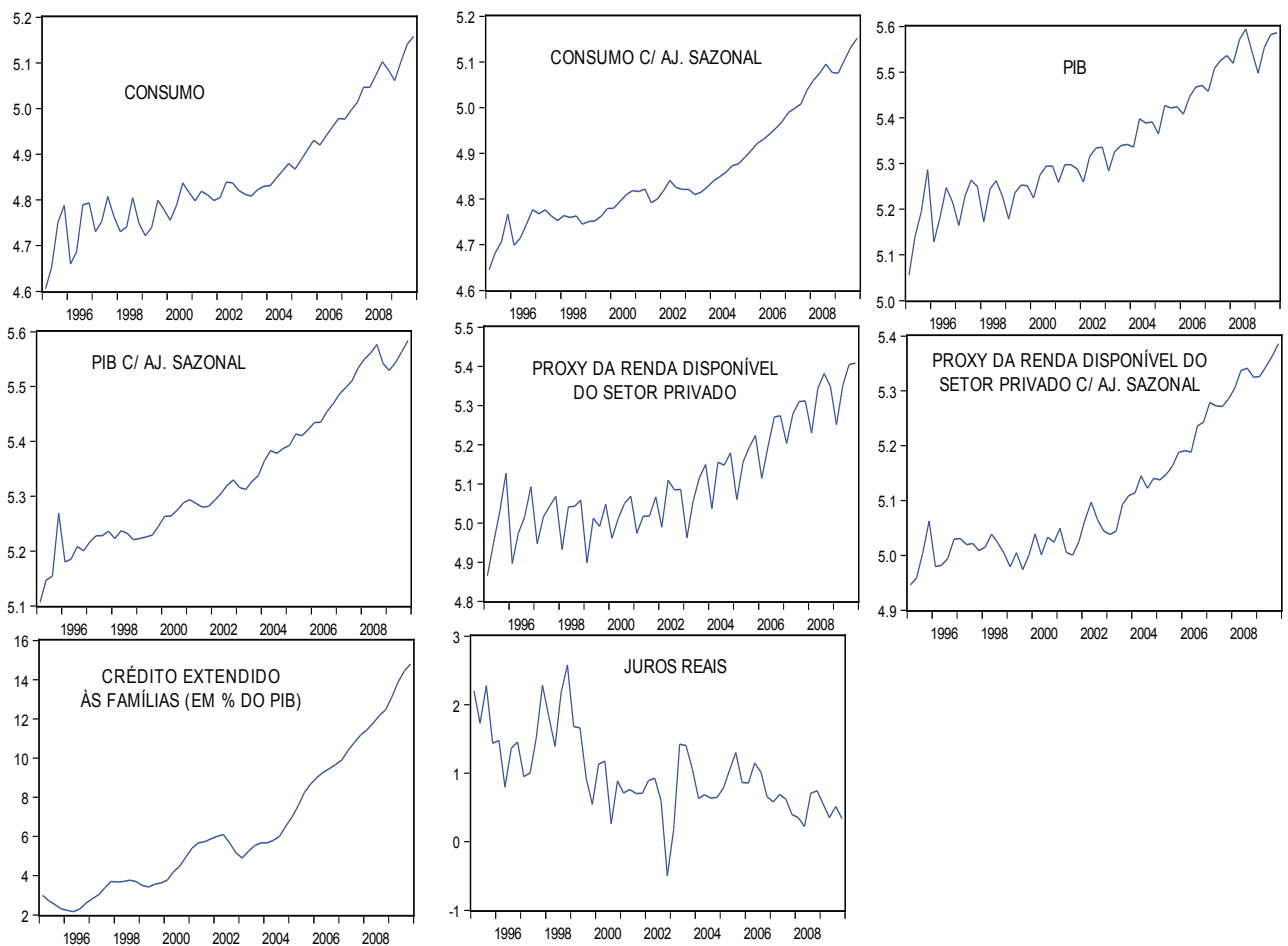

(16) O método de ajustamento sazonal utilizado em todos os casos foi o X-12 multiplicativo. Detalhes sobre esse último método podem ser encontrados em Quantitative Micro Software (2001). 

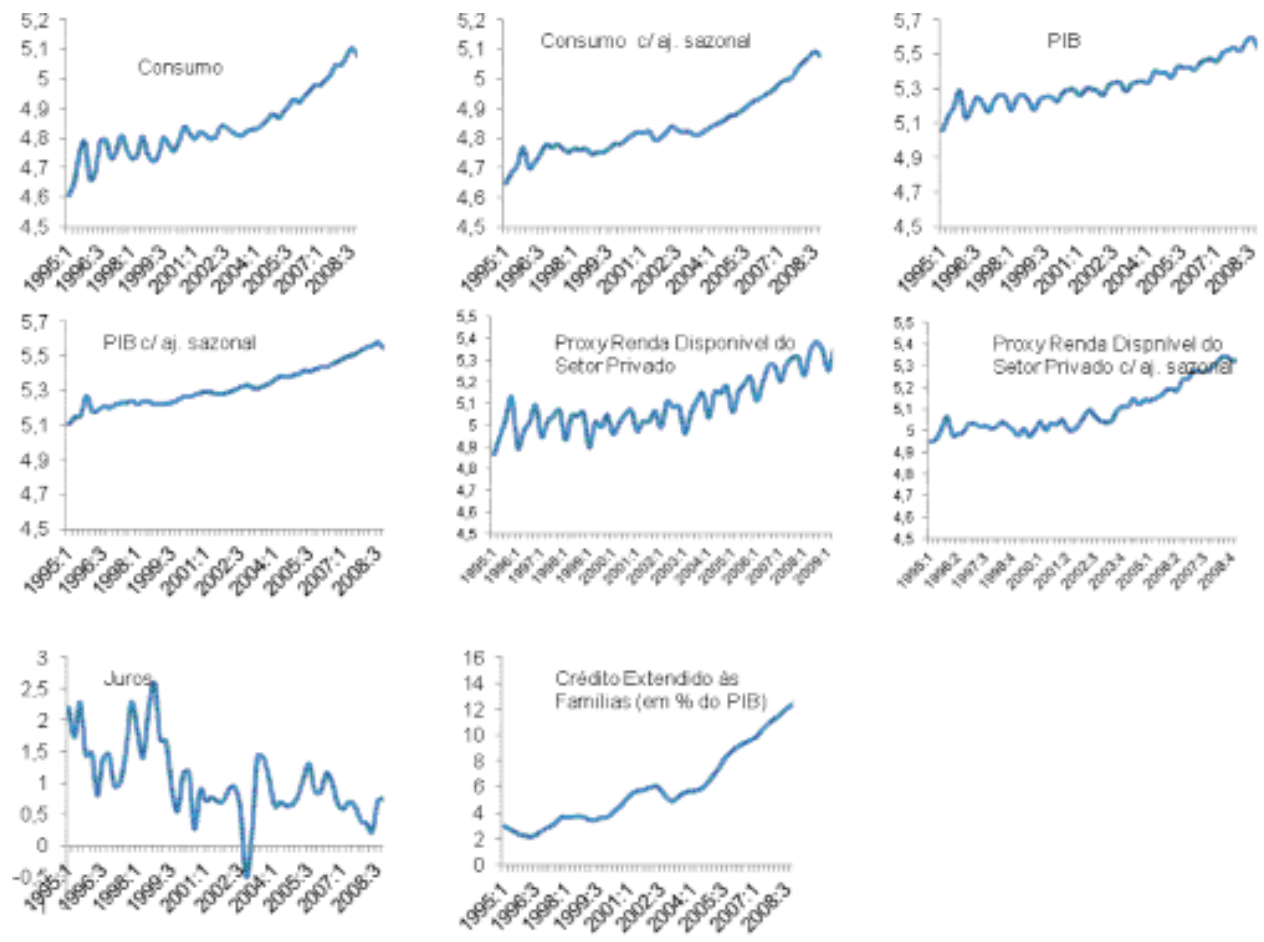

As séries (i) e (ii) acima são disponibilizadas (em R \$ milhões de 1995 e sem ajuste sazonal) na Tabela 9 das contas nacionais trimestrais divulgadas pelo IBGE. Os procedimentos precisos de construção da série (iii) são descritos nos apêndices 2 e 3. Séries sem ajuste sazonal são utilizadas neste trabalho apenas em modelos de espaço-estado de sazonalidade estocástica ${ }^{17}$, enquanto que as séries dessazonalizadas são utilizadas em todos os demais modelos ${ }^{18}$. A série (iv) foi obtida convertendo-se a série (mensal) 11397 do Sistema Gerador de Séries de Tempo do Banco Central do Brasil para a frequência trimestral pela média das observações mensais. A série (v) foi obtida, subtraindo-se a série mensal da variação do IPCA da série mensal da taxa Selic (ao mês) e convertendo a série resultante para a frequência trimestral pela média das observações mensais. Todas as séries começam no primeiro trimestre de 1995 e vão até o quarto trimestre de 2009 (totalizando 60 observações).

Aprende-se muito sobre o comportamento de séries de tempo apenas olhando para os gráficos das mesmas. A simples inspeção visual do Gráfico 1 sugere fortemente, por exemplo, a possibilidade da existência de uma quebra estrutural/ mudança de regime nos dados por volta de 2002-2003. Dignos de nota são, ainda, a

(17) Ver Commandeur e Koopman (2007, cap. 7) para uma exposição intuitiva destes modelos.

(18) Não se trabalha com cointegração sazonal neste texto. 
mudança na sazonalidade das séries do consumo das famílias (principalmente), do PIB e da renda disponível do setor privado (por volta do ano 2000) e a "observação aberrante" verificada para a taxa de juros real na virada de 2002 para 2003 (por conta da forte aceleração da inflação medida pelo IPCA no período em questão).

Tabela 9

Resultados dos testes de raiz unitária

\begin{tabular}{|c|c|c|c|c|c|}
\hline & $A D F-t^{(i)}$ (em niveis) & $\begin{array}{l}\text { ADF-t (em } \\
\text { primeiras } \\
\text { diferenças) }\end{array}$ & $\begin{array}{l}\text { Zivote } \\
\text { Andrews (b) }\end{array}$ & $\begin{array}{l}\text { Franses e } \\
\text { Haldnup }\end{array}$ & $\begin{array}{c}\text { Lee e } \\
\text { Strazicich }\end{array}$ \\
\hline $\begin{array}{l}\text { Consumo } \\
\text { claj. sazonal }\end{array}$ & $\begin{array}{c}-0,776 \\
\text { (c/nivel e tendéncia) }\end{array}$ & $\begin{array}{c}-7,917^{* *} \\
\text { (c/nivel,sitendência) }\end{array}$ & $\begin{array}{l}-5,562^{*} \\
\text { (quebra em } \\
2003: 2 \text { ) }\end{array}$ & NA & 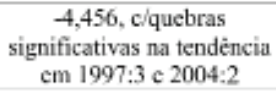 \\
\hline $\begin{array}{c}\text { Renda } \\
\text { Disponivel } \\
\text { c/ aj sizonal }\end{array}$ & $\begin{array}{c}-1,674 \\
\text { (c/nivel e tendência) }\end{array}$ & $\begin{array}{c}-8,452^{\text {*4 }} \\
\text { (c/nivel,sitendência) }\end{array}$ & $\begin{array}{l}-5,535^{\circ} \\
\text { (qucbra } \mathrm{cm} \\
2001: 2 \text { ) }\end{array}$ & NA & $\begin{array}{l}-6,003^{*} \text {, clquebras } \\
\text { significativas na tendência } \\
\text { em 1998:3 e 2003:4. }\end{array}$ \\
\hline $\begin{array}{l}\text { PIB_c/aj. } \\
\text { sazonal }\end{array}$ & $\begin{array}{c}-2,871 \text { (cinivel e } \\
\text { tendencia) }\end{array}$ & $\begin{array}{c}-10,501 * \bullet \\
\text { (c/nivel,sitendencia) }\end{array}$ & $\begin{array}{c}-5,986=7 \\
\text { (quehra em } \\
2004: 1 \text { ) }\end{array}$ & NA & $\begin{array}{c}4,498, \text { c/quebras } \\
\text { significativas na tendència } \\
\text { em } 1997: 2 \text { e } 2003: 1 \text {. }\end{array}$ \\
\hline Crédito & $\begin{array}{c}-1,139 \text { (c/nivel e } \\
\text { tendência) }+1,664 \\
\text { (c/nivel, s/tendência) }\end{array}$ & $\begin{array}{c}-3,00^{*} \\
\text { (cinivel,sitendência) }\end{array}$ & $\begin{array}{c}-5,106^{*} \\
\text { (quebra em } \\
2002: 3 \text { ) }\end{array}$ & NA & $\begin{array}{c}-4,696^{\circ \circ} \text {, c/quebra } \\
\text { significativa na tendência } \\
\text { cm 2005:2. }\end{array}$ \\
\hline Juros & $\begin{array}{c}-3,49^{* *} \\
\text { (c/nivel, s/tendência) }\end{array}$ & NA & $\mathrm{NA}$ & $\begin{array}{l}-4,03^{*-4} \\
\text { (supondo um } \\
\text { outlier em } \\
2002: 4 \text { ) }\end{array}$ & 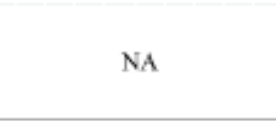 \\
\hline
\end{tabular}

Notas: Os símbolos * $\mathrm{e}^{* *}$ indicam a rejeição da hipótese nula de raiz unitária a $5 \% \mathrm{e} 1 \%$, respectivamente. $\mathrm{NA}$ = "não se aplica"; (a) Os testes ADF-t foram realizados no software E-Views 7.0. Utilizou-se o critério de Schwartz para a seleção do número de defasagens da equação de teste; (b) Os testes de Zivot e Andrews foram executados no software RATS versão 7.0, utilizando o procedimento ZIVOT.SRC disponível gratuitamente em www.estima.com. Supôs-se que a quebra estrutural deu-se tanto no nível quanto na tendência das séries relevantes e utilizou-se o critério de Schwartz para a seleção do número de defasagens da equação de teste; (c) Os testes de Franses e Haldrup foram executados no software E-Views 7.0. Utilizou-se o critério de Schwartz para a seleção do número de defasagens da equação de teste; (d) Os testes de Lee e Strazicich foram executados no software RATS versão 7.0, utilizando o procedimento LSUNIT.SRC disponível gratuitamente em www.estima.com. Supôs-se que a quebra estrutural deu-se tanto no nível quanto na tendência das séries relevantes e utilizou-se o critério geral para específico para a seleção do número (menor ou igual a 4) de defasagens da equação de teste.

Fonte: Os autores.

Essas considerações são importantes para a interpretação dos resultados dos testes de raiz unitária ${ }^{19}$. É fato conhecido, por exemplo, que os testes ADF convencionais de Dickey e Fuller (1981) são viesados na presença de quebras estruturais. (Perron,1989).

Assim sendo, a não rejeição de quebras estruturais nas equações de teste propostas por Lee e Strazicich $(2003,2004)$ sugere que os resultados obtidos com os testes ADF reportados na Tabela 9 são enganosos. Não surpreende, assim, que os

(19) Os testes de raiz unitária foram aplicados apenas a variáveis dessazonalizadas ou sem padrão sazonal evidente. Raízes unitárias sazonais não são discutidas neste trabalho. 
resultados dos testes de Lee e Strazicich confirmem os resultados dos testes ADF em apenas dois casos (consumo das famílias e PIB), contrariando-os em outros dois (crédito e renda disponível do setor privado). Ademais, o número de quebras estruturais também é uma variável importante na análise. Percebe-se, em particular, que os resultados obtidos com os testes de Lee e Strazicich $(2003,2004)$ - que permitem múltiplas quebras estruturais - são, por vezes, diferentes dos obtidos com o teste de Zivot e Andrews (1992) que permite apenas uma única quebra estrutural. Assim, a aplicação do teste de Franses e Haldrup (1994), para controlar pelo fenômeno da "estacionaridade espúria" devida a outliers, não mudou o resultado do teste ADF no caso dos juros ${ }^{20}$.

Uma interpretação literal dos resultados acima sugere que se pode rejeitar a hipótese de raiz unitária no caso das variáveis renda disponível, crédito e taxa de juros real e não se pode rejeitar a hipótese de raiz unitária no caso das variáveis consumo das famílias e PIB. Infelizmente, é notória a dificuldade de ser atestatado se uma série tem ou não raiz unitária em pequenas amostras ${ }^{21}$, em particular, se é possível admitir a possibilidade de múltiplas quebras estruturais. Mais concretamente, uma variável (ou quebra estrutural) que parece estacionária (ou significativa) em uma amostra com cinquenta e poucas observações pode perfeitamente deixar de parecer em uma amostra, digamos, vinte observações maiores. Note-se, em particular, que até mesmo a taxa de juros real - a variável com aparência mais claramente estacionária dentre as que examinamos - parece ser não estacionária se considerarmos apenas o período pós $2002^{22}$.

Esse ponto é crucial porque os testes de (não) cointegração tendem a ser viesados na direção da rejeição da hipótese de não cointegração quando as séries envolvidas são near-integrated (ou seja, estacionárias com raiz próxima de um) ${ }^{23}$. O mesmo ocorre, aliás, quando da existência de quebras estruturais na relação de cointegração (Leybourne; Newbold, 2003).

Assim, os resultados dos testes de cointegração na seção 4.1 devem ser vistos com cautela. A fim de controlar possíveis problemas nas equações de cointegração

(20) Note-se que a série de juros não apresenta tendência, de modo que os testes de Zivot e Andrews e Lee e Strazicich não são aplicáveis neste caso.

(21) Como apontam Hjalmarsson e Osterholm (2007, p.1): Unit root tests go some way toward alleviating the uncertainty regarding the persistence in a given time series but do not provide a definitive answer. Since unit root tests have low power against local alternatives, a failure to reject the null hypothesis of a unit root does not rule out the possibility of a root slightly different from unity. On the other hand, rejecting the null of a unit root does not rule out that the process is still fairly persistent and leaves open the possibility of spurious regressions.

(22) O valor relevante da estatística da teste ADF relevante é - 1.97 no período 2003:2 até 2009:4, que dá um p-valor próximo de $30 \%$.

(23) Ver Hjalmarsson e Osterholm (2007; 2010) e Beechey, Hjalmarsson e Osterholm (2009). 
presumidas, elas são reestimadas, utilizando-se técnicas alternativas, a saber, modelos de alternância de regimes markovianos (na seção 4.2) e modelos de espaçoestado (na seção 4.3). Ademais, segue-se (na seção 4.4) o conselho de Granger (1998, cap. 2), procurando avaliar as conclusões dos melhores modelos ao se calcular o grau de precisão dos mesmos em projeções fora da amostra sujeitas aos valores corretos das variáveis explicativas.

\subsection{Modelos lineares com parâmetros fixos (e possíveis dummies) $)^{24}$}

A Tabela 10 apresenta os resultados de vários testes de cointegração utilizando a proxy da renda disponível do setor privado como variável explicativa. Os resultados obtidos com a utilização do PIB foram invariavelmente piores - a não cointegração foi rejeitada apenas em algumas especificações, incluindo também o crédito como variável explicativa - e não serão apresentados por motivos de economia de espaço.

Tomados em conjunto, os resultados da Tabela 10 dão alguma credibilidade à hipótese de cointegração entre consumo, renda disponível e crédito - e mesmo entre essas três variáveis e a taxa de juros real - em que pese o fato dos testes utilizados serem notoriamente afetados pela existência de quebras estruturais na relação de cointegração (como já mencionado). Note-se que os resultados do teste de Johansen (e as próprias estimativas do vetor de cointegração obtidas pelo método de máxima verossimilhança proposto pelo referido autor) são, particularmente, problemáticos em vista das fortes evidências de quebras estruturais nos "VARs de partida" requeridos para a aplicação do teste ${ }^{25}$.

Para propósitos imediatos, é importante destacar que a ordem de grandeza das elasticidades e semielasticidades estimadas por mínimos quadrados ordinários (com e sem quebras) parece razoável e, como discutido a seguir, é relativamente robusta a adoção de técnicas econométricas alternativas ${ }^{26}$. Destaque-se, em particular, que

(24) Para uma apresentação detalhada das técnicas utilizadas nesta seção, ver Enders (2010, cap. 5 e 6), Patterson (2000, cap. 8) e Gregory e Hansen (1996).

(25) A rigor, a validade do teste de Johansen está condicionada à hipótese de "congruência" do VAR de partida. Por sua vez, ela requer, dentre outras coisas, que não haja quebras estruturais durante o período em análise. A aplicação de testes de Chow aos VARs de partida possíveis - no software J-Multi, versão 4.24 - revelou a existência de múltiplas quebras estruturais nesses últimos. Os resultados de tais testes não serão apresentados aqui por falta de espaço, mas podem ser obtidos junto aos autores mediante consulta.

(26) Neste trabalho, os coeficientes dos vetores de cointegração estimados foram denominados pelos termos genéricos de "elasticidade" e "semielasticidade" - tendo em vista a interpretação dos mesmos como "sensibilidades relativas" da variável dependente em relação a mudanças nas variáveis explicativas. Segundo Johansen (2005), tal interpretação deve ser vista com cautela. Primeiro, cumpre frisar que os referidos coeficientes não devem ser interpretados como parâmetros derivados de modelos estruturais teóricos - ou, de outro modo, que os vetores de cointegração reportados neste trabalho devem ser vistos como "formas reduzidas" dos referidos modelos estruturais (cuja identificação não é discutida). Há, ademais, a possibilidade teórica de que os vetores de cointegração estimados [no caso dos modelos com mais de uma variável explicativa] sejam, na verdade, combinações lineares de outros vetores de cointegração não identificados (Harris, 1995, p. 62-63). 
a importância da renda disponível na determinação do consumo parece cair quando se controla pela importância (crescente, principalmente a partir do primeiro governo Lula) do crédito às famílias.

Tabela 10

Resultados dos testes de (não) cointegração ${ }^{\text {(a) }}$

\begin{tabular}{|c|c|c|c|}
\hline Teste & Especificação & Resultado & Relação de Cointegração \\
\hline $\mathrm{E} \& \mathrm{G}$ & $c=f(y d)$ & -3.73 (rejcita não cointegração a 5\%) & $c=-0.137+0.976^{\circ} y d$ \\
\hline $\mathrm{E} \& \mathrm{G}$ & $c=f(y d, c r e d)$ & -5.38 (rejeita não cointegraçằ a $1 \%$ ) & $c=2.375+0.462^{\circ} \mathrm{yd} d+0.019^{\circ} \mathrm{cmed}$ \\
\hline E\&G & $\mathrm{c}-\mathrm{f}(\mathrm{yd}, \mathrm{jur})$ & -4.27 (rejeita não cointegraçẫo a $5 \%$ ) & $c=0.202+0.916^{*} y d-0.025 * j u r$ \\
\hline $\mathrm{E} \& \mathrm{G}$ & $c-f(y d$, cred, jur) & -4.08 (rejeita nũo cointegração a $7 \%$ ) & $\begin{array}{l}c-2.355+0.472^{*} y d+0.017^{*} \text { cred }- \\
0.018^{*} \mathrm{jur}\end{array}$ \\
\hline G\&H & $c-f(y d)$ & $\begin{array}{l}-3.95 \text { (não rejeita não cointegração a } 5 \% \text { ) } \\
\text { Quebra estimada em } 2003: 3 \text {. }\end{array}$ & 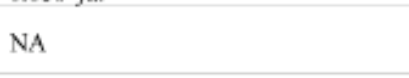 \\
\hline G\&H & $c-f(y d$, cred) & $\begin{array}{l}-5.60 \text { (rejeita não cointegração a } 5 \% \text { ). } \\
\text { Quebra estimada em } 2007: 3\end{array}$ & 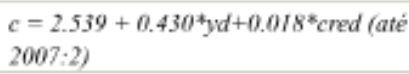 \\
\hline $\mathrm{G} \& \mathrm{H}$ & $c-f(y d, j u r)$ & $\begin{array}{l}-3.67 \text { (nào rejeita não cointegraçũo a } 5 \%)^{(c)} \\
\text { Quebra estimada em 1997:2. }\end{array}$ & $\mathrm{N} \Lambda$ \\
\hline $\mathrm{G} \& \mathrm{H}$ & $\mathrm{c}-\mathrm{f}(\mathrm{yd}, \mathrm{cred}, \mathrm{jur})$ & $\begin{array}{l}-7.13 \text { (rejeita não cointegração a 1\%). } \\
\text { Quebra estimada em } 2001: 2\end{array}$ & $\begin{array}{l}c=1.035+0.734^{*} y d+0.021^{*} \text { cred }- \\
0.020 * \text { jur (até } 2001: 1)_{e} \\
c-2.760+0.386 * y d+0.021 * \text { cred }- \\
0.020 * \text { jur (após } 2001: 2 \text { ) }\end{array}$ \\
\hline $\mathrm{JOH}$ & $c-f(y d)$ & $\begin{array}{l}9.32 \text { (não rejeita ausència de cointegração). } \\
\text { p-valor-0.26 }\end{array}$ & NA \\
\hline $\mathrm{JOH}$ & $c-f(y d, c r e d)$ & $\begin{array}{l}27.15 \text { (rejeita ausência de cointegração a } \\
1 \% \text { ): } 11.83 \text { (nầo rejeita um vetor de } \\
\text { cointegraçằo a } 10 \% \text { ). }\end{array}$ & $c-4.175+0.096^{*} y d+0.03^{*}{ }^{*}$ cred \\
\hline $\mathrm{JOH}$ & $\mathrm{c}-\mathrm{f}(\mathrm{yd}, \mathrm{jur})$ & $\begin{array}{l}17.55 \text { (não rejeita auséncia de cointegração). } \\
\text { p-valor }-0.14\end{array}$ & NA \\
\hline $\mathrm{JOH}$ & $\mathrm{c}=\mathrm{f}(\mathrm{yd}, \mathrm{cred}, \mathrm{jur})$ & $\begin{array}{l}30.10 \text { (rejeita auscencia de cointegraçīo a } \\
5 \% \text { ); } 13.98 \text { (não rejeita um vetor de } \\
\text { cointegração a } 30 \% \text { ). }\end{array}$ & $\begin{array}{l}c=4.46+0.0365^{4} y d+0.033^{*} c r e d+ \\
0.002^{*} \text { jur }\end{array}$ \\
\hline
\end{tabular}

Notas: NA = "não se aplica"; (a) Os testes de Gregory e Hansen foram executados no software RATS versão 7.0, utilizando o procedimento GREGORYHANSEN.SRC disponível gratuitamente em www. estima.com. Supôs-se que a quebra estrutural deu-se tanto no nível quanto na tendência das séries relevantes. Os testes de Engle e Granger e Johansen foram realizados no software E-Views 7.0; (b) Os valores críticos para rejeição a $1 \%$ e $5 \%$ são respectivamente -5.47 e -4.95 ; (c) Os valores críticos para rejeição a $1 \%$ e $5 \%$ são respectivamente -5.97 e -5.50 .

Fonte: Os autores. Os testes E\&G, G\&H e JOH significam, respectivamente, Engle \& Granger, Gregory \& Hansen e Johansen máximo autovalor.

\subsection{Modelos de alternância de regimes markovianos ${ }^{27}$}

A Tabela 11 apresenta os resultados obtidos com a estimação de modelos de alternância de (2 e 3) regimes markovianos ${ }^{28}$.

(27) Para uma apresentação detalhada das técnicas utilizadas nesta seção, ver Hamilton (1994, cap. 22) e Krolzig (1997).

(28) Tais modelos foram rodados no software PC-GIVE versão 13. As especificações escolhidas em cada caso foram as que apresentaram os menores valores para o critério de Akaike (além da rejeição da hipótese de linearidade no teste da razão de verossimilhança, convergência tão forte quanto possível e de erros tão bem comportados quanto possível). 
Tabela 11

Resultados dos modelos de alternância de regimes markovianos

\begin{tabular}{|c|c|c|}
\hline Especificação & Resultado & Dutaçâo dos regimes/Comentários \\
\hline $\begin{array}{l}c-f(y d) \\
2 \text { regimes }\end{array}$ & $\begin{array}{l}\text { Regime } 0: c--0,618+1,069^{*} y d \\
\text { Regime } 1: c-0,944+0,767^{*} y d \\
\text { (c/variância dos erros constante) } \\
\text { Convergência forte. }\end{array}$ & $\begin{array}{l}\text { Reg. 0 (35 trimestres): } 1995(1)-1998(4) ; 2003(3)-2005(3) \text {; } \\
2007(3)-2009(4) \text {; } \\
\text { Reg. } 1 \text { (25 trimestres): 1999(1)-2003(2); 2005(4)-2007(2). } \\
\text { Erros aparentemente autocorrelacionados }{ }^{(2)}\end{array}$ \\
\hline $\begin{array}{l}c=f(y d) \\
3 \text { regimes }\end{array}$ & $\begin{array}{l}\text { Reg.0: } c=0,025+0,938^{*} \mathrm{yd} \\
\text { Reg. } 1: \mathrm{c}=0,053+0,938^{*} \mathrm{yd} \\
\text { Reg. } 2: \mathrm{c}=0,083+0,938^{*} \mathrm{yd} \\
\text { (c/variância dos erros variável) } \\
\text { Convergência forte. }\end{array}$ & $\begin{array}{l}\text { Reg.0 ( } 9 \text { trimestres): 1995(1)-1996(1); 2003(3)-2004(2); } \\
\text { Reg. I (24 trimestres): 1996(2)-1998(4); 2004(3)-2007(3); } \\
\text { Reg. } 2 \text { (27 trimestres): 1999(1)-2003(2); 2007(4)-2009(4). } \\
\text { Erros aparentemente bem-comportados. }\end{array}$ \\
\hline $\begin{array}{l}c=f(y d, \text { cred }) \\
2 \text { regimes }\end{array}$ & $\begin{array}{l}\text { Reg. } 0: \mathrm{c}-1,125+0,737^{*} \mathrm{yd}-0,040^{\circ} \mathrm{cr} \\
\text { Reg. } \mathrm{I}: \mathrm{c}=2,733+0,39 \mathrm{I}^{\circ} \mathrm{yd}+0,021^{*} \mathrm{cr} \\
\text { (c/variância dos crros variável) } \\
\text { Convergéncia forte. }\end{array}$ & $\begin{array}{l}\text { Reg.0 (5 trimestres): 1995(1) - 1996(1): } \\
\text { Reg. } 1 \text { ( } 55 \text { trimestres): } 1996(2)-2009(4) \text {. Erros } \\
\text { aparentemente autocorrelacionados }{ }^{(2)} \text { e não normais. }\end{array}$ \\
\hline $\begin{array}{l}c-f(y d, \text { cred }) \\
3 \text { regimes }\end{array}$ & $\begin{array}{l}\text { Reg. } 0: \mathrm{c}=1,143+0,734^{*} \mathrm{yd}-0,04^{*} \mathrm{cr} \\
\text { Reg.1: } \mathrm{c}-2,655+0,405^{*} \mathrm{yd}+0,020^{*} \mathrm{cr} \\
\text { Reg.2: } \mathrm{c}=2,508+0,440^{*} \mathrm{yd}+0,018^{*} \mathrm{cr} \\
\text { (c/variância dos erros variável) } \\
\text { Convergência forte. }\end{array}$ & $\begin{array}{l}\text { Reg. } 0 \text { (6 trimestres): 1995(1) - 1996(2); } \\
\text { Reg. } 1 \text { (31 trimestres): 1997(3) - 1999(2); 2001(3) - } \\
\text { 2002(3); 2003(2) - 2007(3); } \\
\text { Reg.2 (23 trimestres); 1996(3) - 1997(2); 1999(3)-2001(2); } \\
\text { 2002(4)-2003(1); 2007(4)-2009(4). } \\
\text { Erros aparentemente autocorrelacionados }{ }^{(3)}\end{array}$ \\
\hline $\begin{array}{l}c-f(y d, \text { cred, } \\
\text { jur) } \\
2 \text { regimes }\end{array}$ & $\begin{array}{l}\text { Reg. } 0: \mathrm{c}=2,087+0,531^{*} \mathrm{yd}+ \\
0,014^{*} \mathrm{cred}-0,047^{*} \text { jur; } \\
\text { Reg. } 1: \mathrm{c}-2,987+0,343^{*} \mathrm{yd}+ \\
0,021^{*} \mathrm{cred}-0,014^{*} \text { jur } \\
\text { (c/variaincia dos crros variável) } \\
\text { Convergéncia forte. }\end{array}$ & $\begin{array}{l}\text { Reg. } 0 \text { (10 trimestres): 1995(1)-1995(2); 2001(3)-2002(3); } \\
2005(4)-2006(1) ; 2007(3)-2007(3) \text {. } \\
\text { Reg. I (50 trimestres): 1995(3)-2001(2);2002(4)-2005(3); } \\
2006 \text { (2)-2007(2); 2007(4)-2009(4). } \\
\text { Erros aparentemente bem-comportados. }\end{array}$ \\
\hline $\begin{array}{l}\mathrm{c}-\mathrm{f}(\mathrm{yd}, \mathrm{cred}, \\
\text { jur) } \\
3 \text { regimes }\end{array}$ & $\begin{array}{l}\text { Reg.0: } \mathrm{c}=-0,191+0,976^{*} \mathrm{yd}+ \\
0,019^{*} \mathrm{cred}-0,0166^{*} \text { jur; } \\
\text { Reg. I: } \mathrm{c}-2,580+0,423^{*} \mathrm{yd}+ \\
0,019^{*} \mathrm{cred}-0,0166^{*} \text { jur; } \\
\text { Reg.2: } \mathrm{c}=2,739+0,396^{*} \mathrm{yd}+ \\
0,019^{*} \text { cred }-0,0166^{\circ} \text { jur } \\
\text { (variảncia dos erros é variável) }\end{array}$ & $\begin{array}{l}\text { Reg.0 (4 trimestres): 1995(1)-1995(4); } \\
\text { Reg. } 1 \text { (28 trimestres): 1996(1)-1996(2); } 1998(2)-1998(2) \text {; } \\
\text { 2001(3)-2002(4); 2003(3)-2007(3); 2009(1)-2009(2). } \\
\text { Reg. } 2 \text { (28 trimestres);1996(3)-1998(1); 1998(3)-2001(2); } \\
\text { 2003(1)-2003(2); 2007(4)-2008(4); 2009(3)-2009(4). } \\
\text { Erros aparentemente nâo normais }\end{array}$ \\
\hline
\end{tabular}

(a) Presença de autocorrelação residual indicada pelo teste Portmanteau

Fonte: Os autores.

Note-se que em vista das evidências de não cointegração reportadas na seção 4.1 para as séries do consumo, da renda disponível e taxa de juros (a despeito das quebras estruturais e possibilidade das séries serem near-integrated) - e das evidências de cointegração reportadas na seção 4.1 para as séries do consumo, da renda disponível e do crédito - optou-se por descartar a hipótese de que a dinâmica do consumo seria função apenas da renda disponível e da taxa de juros.

Tomados em conjunto, os resultados da Tabela 11 parecem corroborar várias das conclusões obtidas com as equações de cointegração. Não somente os valores estimados da elasticidade-renda (em torno de 0,4) e das semielasticidades crédito e juro do consumo (em torno de $+0,02$ e $-0,02$, respectivamente) são similares aos obtidos antes (em particular com a aplicação do teste de Gregory e Hansen (1996)), como a datação das quebras também parece familiar (no final dos anos 1990, início 
dos anos 2000 e em 2007, na maioria dos casos). A estimação de alguns modelos sugere, ainda, que os dados de 1995 são atípicos - o que não é captado pelos testes de Zivot e Andrews (1992), Lee e Strazicich (2004; 2005) e Gregory e Hansen (que, por construção, procuram quebras apenas no período 1997-2007, ignorando as extremidades da amostra).

\subsection{Modelos de Espaço-Estado ${ }^{29}$}

Tabela 12

Resultados dos Modelos de Espaço-Estado

\begin{tabular}{|c|c|c|}
\hline Especificação & Resultado & Comentários \\
\hline $\begin{array}{l}\mathrm{c}=\mathrm{f}(\mathrm{yd}) \\
\text { variáveis c/ ajuste sazonal }\end{array}$ & $\begin{array}{l}\text { Modelo com constante fixa }(2,101 \text { ) e elasticidade-renda } \\
\text { distribuída como um random-walk (que flutuou quase } \\
\text { monotonicamente entre } 0,53 \text { e } 0,56 \text { ) revelou-se o mais } \\
\text { bem ajustado. }\end{array}$ & $\begin{array}{l}\text { Convergência muito forte. Erros normais, } \\
\text { mas autocorrelacionados e com alguma } \\
\text { evidência de heterocedasticidade. }\end{array}$ \\
\hline $\begin{array}{l}\mathrm{c}=\mathrm{f}(\mathrm{yd}) \\
\text { variáveis s/ ajuste sazonal }\end{array}$ & $\begin{array}{l}\text { Modelo com constante e sazonalidade estocásticas e } \\
\text { elasticidade-renda fixa (em } 0,524) \text { revelou-se o mais bem } \\
\text { ajustado. }\end{array}$ & $\begin{array}{l}\text { Convergência muito forte. Erros bem } \\
\text { comportados. }\end{array}$ \\
\hline $\begin{array}{l}\mathrm{c}=\mathrm{f}(\mathrm{yd}, \mathrm{cred}) \\
\text { variáveis } \mathrm{c} / \text { ajuste sazonal }\end{array}$ & $\begin{array}{l}\text { Modelo com constante }(2,242) \text { e semielasticidade crédito } \\
(0,012) \text { fixas e elasticidade-renda distribuída como um } \\
\text { random-walk (que flutuou quase monotonicamente entre } \\
0,48 \text { e } 0,51 \text { ) revelou-se o mais bem ajustado. }\end{array}$ & $\begin{array}{l}\text { Convergência muito forte. Erros normais, } \\
\text { mas autocorrelacionados e com alguma } \\
\text { evidência de heterocedasticidade. }\end{array}$ \\
\hline $\begin{array}{l}\mathrm{c}=\mathrm{f}(\mathrm{yd}, \mathrm{cred}) \\
\text { variáveis s/ ajuste sazonal }\end{array}$ & $\begin{array}{l}\text { Modelo com constante e sazonalidade estocásticas e } \\
\text { elasticidade-renda e semielasticidade crédito fixas (em } \\
0,451 \text { e } 0,013 \text {, respectivamente) se revelou o mais bem } \\
\text { ajustado. }\end{array}$ & $\begin{array}{l}\text { Convergência muito forte. Erros bem } \\
\text { comportados. }\end{array}$ \\
\hline $\begin{array}{l}\mathrm{c}=\mathrm{f}(\mathrm{yd}, \mathrm{cred}, \mathrm{jur}) \\
\text { variáveis c/ ajuste sazonal }\end{array}$ & $\begin{array}{l}\text { Modelo com constante }(2,501) \text { e elasticidade renda } \\
(0,443) \text { fixas e semielasticidades crédito e juros } \\
\text { distribuídas como random-walks (e flutuando entre } 0,015 \\
\text { e } 0,018 \text { e entre zero e }-0,04 \text {, respectivamente) se revelou } \\
\text { o mais bem ajustado. }\end{array}$ & $\begin{array}{l}\text { Convergência muito forte. Erros bem } \\
\text { comportados. }\end{array}$ \\
\hline $\begin{array}{l}\mathrm{c}=\mathrm{f}(\mathrm{yd}, \mathrm{cred}, \mathrm{jur}) \\
\text { variáveis s/ ajuste sazonal }\end{array}$ & $\begin{array}{l}\text { Modelo com constante e sazonalidade estocásticas e } \\
\text { elasticidade-renda e semielasticidades crédito e juros } \\
\text { fixas (em } 0,415,0,016 \text { e }-0,018 \text {, respectivamente) se } \\
\text { revelou o mais bem ajustado. }\end{array}$ & $\begin{array}{l}\text { Convergência muito forte. Erros bem } \\
\text { comportados. }\end{array}$ \\
\hline
\end{tabular}

Fonte: Os autores.

A Tabela 12, por sua vez, apresenta os resultados obtidos com a estimação de modelos de espaço-estado ${ }^{30}$. Novamente, os resultados parecem corroborar as ordens de grandeza das estimativas iniciais obtidas no trabalho para a elasticidaderenda e semielasticidades crédito e juros do consumo agregado das famílias brasileiras - ainda que os valores das duas últimas variáveis tenham-se mostrado ligeiramente inferiores aos reportados nas seções anteriores (flutuando em torno de 0,015 em valor absoluto, ao invés de 0,020 ).

Dois resultados gerais reportados na Tabela 12 parecem particularmente importantes. Primeiro, os resultados obtidos com modelos (de sazonalidade

(29) Para uma apresentação detalhada das técnicas utilizadas nesta seção, ver Harvey (1989) e Hamilton (1994, cap. 13).

(30) Tais modelos foram rodados no software STAMP versão 8.2. As especificações escolhidas em cada caso foram as que apresentaram os menores valores para os critérios de Akaike e Schwartz (além de convergência tão forte e de erros tão bem comportados quanto possível). 
estocástica $^{31}$ ) com variáveis sem ajuste sazonal foram bastante semelhantes aos obtidos com variáveis dessazonalizadas - sugerindo que a dessazonalização das séries não introduziu viés significativo na análise. Em segundo lugar, a maior parte da variação paramétrica parece ocorrer no nível e na sazonalidade estimadas e não nas elasticidades propriamente ditas. Esse último resultado é simultaneamente compatível com as evidências de quebras estruturais reportadas nas seções anteriores e significativo do ponto de vista analítico.

\subsection{Modelos de projeção para o consumo agregado trimestral das famílias brasileiras}

Tomados em conjunto, os resultados das três seções anteriores parecem indicar a existência de correlações significativas entre a dinâmica trimestral do consumo agregado das famílias brasileiras medido a preços constantes e a dinâmica trimestral da renda disponível do setor privado (aproximada), do volume de crédito disponibilizado às famílias brasileiras (em \% do PIB) e da taxa de juros real da economia. Mais precisamente, acréscimos de $1 \%$ na proxy da renda disponível do setor privado utilizada neste trabalho parecem estar associados a acréscimos de cerca de $0,4 \%$ no consumo das famílias brasileiras; acréscimos de $1 \%$ do PIB no volume de crédito disponibilizado às famílias brasileiras parecem estar associados a acréscimos de $1,5 \%$ a $2 \%$ no consumo destas últimas; acréscimos de 1 ponto percentual na taxa de juro real mensal parecem estar associados a reduções de $1,5 \%$ a $2 \%$ no consumo das famílias brasileiras.

Naturalmente, resultados de regressões macroeconométricas não devem ser tomados como "verdades absolutas". Conquanto a robustez dos resultados apresentados nas seções anteriores pareça não trivial e digna de nota - afinal, tais resultados foram verificados em, literalmente, dezenas de modelos (incluindo vários não reportados nas seções anteriores) estimados por técnicas muito diferentes entre si - também é verdade que uma regressão não deixa de ser espúria apenas porque foi "encontrada" por estimadores diferentes.

Em contrapartida, a chance de regressões espúrias comportarem-se bem nos testes de cointegração discutidos na seção 4.1 não é alta (mesmo nas hipóteses de quebra estrutural e das séries serem near-integrated na amostra relevante). $\mathrm{O}$ mesmo pode ser dito sobre a chance de regressões espúrias comportarem-se bem em projeções "fora da amostra". Assim, o próximo passo natural da estratégia econométrica seguida neste trabalho é averiguar o quão precisas são as projeções dos modelos estimados anteriormente oito e quatro trimestres "fora da amostra" (sujeitas aos valores precisos das variáveis explicativas). Se tais projeções mostrarem-se precisas, haverá motivos a mais para que se confie nos (flagrantemente robustos) resultados gerais reportados nas seções anteriores.

(31) Ver Commandeur e Koopman (2007, cap. 4) para detalhes. 
Novas evidências empíricas sobre a dinâmica trimestral do consumo agregado...

Tabela 13

Resultados das projeções fora da amostra

\begin{tabular}{|c|c|c|}
\hline əcificaçào & \multirow{3}{*}{$\begin{array}{l}\text { Markov-Switching, o/ } 3 \text { regimes, com mesma } \\
\text { elasticidade-renda e variância dos erros e } \\
\text { termo constante variảveis. } \\
\text { Convergẻncia forte. }\end{array}$} & $\begin{array}{c}\text { Erro das projeçōes feitas para cada um dos que } \\
\text { trimestres de ( } 2008 \text { e) } 2009 \text { e para o(s) ano( } 5 \\
\text { inteiro(s), sujeitas aos valores precisos das } \\
\text { variáveis cxplicativas }\end{array}$ \\
\hline $\begin{array}{l}\text { (îyd), até } \\
7: 4\end{array}$ & & $\begin{array}{l}2008-1:-1.55 \% ; 2008-2:-0.13 \% ; 2008-3:-1.6 t \\
2008-4:-1.44 \% ; \text { Ano de } 2008:-1.20 \% \\
2009-1:-1.17 \% ; 2009-2:-2.40 \% ; 2009-3:-3.28 \\
2009-4:-3.15 \% ; \text { Ano de } 2009:-2.52 \% \\
\text { Erro quadrático médio: } 12,28\end{array}$ \\
\hline $\begin{array}{l}\text { f(yd), até } \\
B: 4\end{array}$ & & $\begin{array}{l}2009-1:-0.06 \% ; 2009-2:-1.58 \% ; 2009-3:-2.65 \\
2009-4:-2.76 \% ; \text { Ano de } 2009:-1.80 \% \\
\text { Erro quadrático médio: } 12,588\end{array}$ \\
\hline $\begin{array}{l}\text { f(yd, cred), } \\
2007: 4\end{array}$ & Engle e Granger & $\begin{array}{l}2008-1:-2.51 \% ; 2008-2 ;-2.11 \% ; 2008-3 ;-3.0 \% \\
2008-4:-1.50 \% ; \text { Ano de } 2008:-2.30 \% ; \\
2009-1:-0.10 \% ; 2009-2:-0.83 \% ; 2009-3:-1.6 t \\
2009-4:-1.98 \% ; \text { Ano de } 2009 ;-1.16 \% \\
\text { Erro quadrático médio: } 9,944\end{array}$ \\
\hline $\begin{array}{l}\text { [(yd, cred), } \\
2008: 4\end{array}$ & Engle e Granger & $\begin{array}{l}2009-1: 0.18 \% ; 2009-2: 0.85 \% ; 2009: 3:-0.60^{\circ} \\
2009: 4:-0.85 \% ; \text { Ano de } 2009:-0.12 \% \\
\text { Erro quadrático médio: } 1,277\end{array}$ \\
\hline $\begin{array}{l}\text { fiyd, cred, } \\
\text { até 2007:4 }\end{array}$ & $\begin{array}{l}\text { Modelo de Espaço-Estado com constante e } \\
\text { elasticidade renda fixas e semielasticidades } \\
\text { crédito e juros, distribuidas como random- } \\
\text { walks. Convergència muito forte. }\end{array}$ & $\begin{array}{l}2008-1:-1.77 \% ; 2008=2:-1.28 \% ; 2008-3:-2.87 \\
2008-4:-1.32 \% ; \text { Ano de } 2008 ;-1.81 \% \\
2009-1: 0.25 \% ; 2009-2:-0.33 \% ; 2009-3:-1.43 \\
2009-4:-1.62 \% ; \text { Ano de } 2009:-0.80 \% \\
\text { Erro quadrático médio: } 6.564\end{array}$ \\
\hline $\begin{array}{l}\text { ffyd, cred, } \\
\text { até 2008:4 }\end{array}$ & Engle-Granger & $\begin{array}{l}2009-1: 0.34 \% ; 2009-2 ;-0.12 \% ; 2009-3 ;-1.29 \\
2009-4:-1.28 \% \\
\text { Ano de } 2009:-0.60 \% \\
\text { Erro quadrático médio: } 2,501\end{array}$ \\
\hline
\end{tabular}

Fonte: Os autores.

Os resultados das seções anteriores levam os autores deste trabalho a uma pré-seleção como potencialmente "plausíveis" dos resultados de cinco técnicas econométricas aplicadas a três conjuntos de variáveis explicativas. As técnicas econométricas são os modelos de espaço-estado (e.g. Harvey, 1989) com e sem sazonalidade estocástica e modelos de Engle e Granger (1987), Gregory e Hansen (1996) e alternância de regimes Markovianos (e.g. Krolzig, 1997) ${ }^{32}$. Os três conjuntos de variáveis explicativas são (i) yd; (ii) yd e cred; (iii) yd, cred e jur. A fim de selecionar os resultados reportados na Tabela 13, aplicam-se as 5 técnicas econométricas a cada um dos três conjuntos de variáveis explicativas (15 modelos no total), restringindo-se as amostras aos períodos 1995:1-2007:4 e 1995:1-2008:4. Ademais, a partir desses 15 modelos, projetam-se os resultados para os quatro trimestres de 2008 e 2009, selecionando-se o melhor para cada conjunto de variáveis explicativas um e dois anos fora da amostra.

(32) Naturalmente, e como mencionado antes, os modelos sem sazonalidade estocástica foram aplicados às variáveis dessazonalizadas e os modelos com sazonalidade estocástica foram aplicados às variáveis sem ajuste sazonal. 
Os resultados da Tabela 13 são interessantes de várias maneiras. Em primeiro lugar, reforçam a hipótese de que as regressões em questão são legítimas. Com efeito, são raras as regressões espúrias com erros de projeção anuais inferiores a $1 \%$ e $2 \%$ em valores absolutos um e dois anos à frente ${ }^{33}$. Em segundo lugar, os resultados sugerem fortemente que o poder explicativo da oferta de crédito (sobretudo) e da taxa real de juros não deve ser negligenciado - visto que o modelo com apenas a renda disponível como variável explicativa projeta pior do que os demais. Em terceiro lugar, os resultados parecem sugerir que o efeito da taxa real de juros sobre o consumo das famílias é variável - sendo assim, o poder preditivo dos modelos com taxa de juros inclusa entre as variáveis explicativas não é flagrantemente superior a dos modelos que incluem apenas o volume de crédito às famílias.

Cumpre notar que o status teórico das regressões propostas acima é o de um vetor de cointegração (ou de uma combinação linear de vetores de cointegração, caso haja mais de $u^{34}$ ). Esse ponto é importante porque, em geral, modelos de correção de erros comportam-se melhor do que vetores de cointegração em projeções de curto prazo (Pattersson, 2000, cap. 8).

Ocorre que o ajustamento de modelos de correção de erros aos dados acima - conquanto tenha gerado modelos com resíduos bem ajustados e sinais esperados, mesmo quando apenas variáveis explicativas defasadas foram utilizadas a fim de evitar o viés de endogeneidade ${ }^{35}$ - sugere coeficientes de correção de erros relativamente elevados em níveis absolutos (rápida convergência, portanto, ao "equilíbrio de longo prazo"), o que talvez justifique o motivo das projeções dos modelos de correção de erros não serem superiores aos obtidos com os vetores de cointegração propriamente ditos no caso dos dados discutidos neste trabalho.

\section{Notas finais}

Neste trabalho, apresentaram robustas evidências de correlações significativas entre a dinâmica trimestral do consumo agregado das famílias brasileiras, medido a preços encadeados de 1995 e a dinâmica trimestral do volume de crédito disponibilizado às famílias brasileiras (em \% do PIB), da taxa de juros real da economia e, principalmente, da medida aproximada da renda disponível do

(33) Em alguns casos, a precisão das projeções foi similar a de modelos ARMA, com a vantagem de que projeções a partir de cenários para a taxa de juros, o volume de crédito e a renda disponível do setor privado são mais facilmente inteligíveis do que cenários para os choques de um modelo ARMA. A fim de tentar manter o tamanho do texto em níveis aceitáveis, optou-se por não apresentar os modelos ARMA ajustados aos dados acima. Os referidos modelos, entretanto, podem ser obtidos junto aos autores mediante consulta.

(34) Note-se que as dificuldades com os "VARs de partida" prejudicaram a aplicação do teste de Johansen. Assim, não se sabe ao certo o número de vetores de cointegração existente entre as quatro variáveis utilizadas neste trabalho.

(35) A fim de tentar manter o tamanho do texto em níveis aceitáveis, optou-se por não apresentar os modelos de correção de erros. Os referidos modelos, entretanto, podem ser obtidos junto aos autores mediante consulta. 
setor privado discutida na seção 1 (também medida a preços encadeados de 1995 , utilizando-se o deflator do consumo). Mais precisamente, acréscimos de $1 \%$ na proxy da renda disponível do setor privado utilizada neste trabalho parecem estar associados a acréscimos de cerca de $0,4 \%$ no consumo das famílias brasileiras; acréscimos de $1 \%$ do PIB no volume de crédito disponibilizado às famílias brasileiras parecem estar associados a acréscimos de $1,5 \%$ a $2 \%$ no consumo destas últimas; acréscimos de ponto percentual na taxa de juro real mensal parecem estar associados a reduções de $1,5 \%$ a $2 \%$ no consumo das famílias brasileiras. Ademais, o erro de projeção dos referidos modelos - interpretados aqui como vetores de cointegração ${ }^{36}$ - é inferior a $1 \%$ e $2 \%$ um e dois anos fora da amostra, respectivamente, quando sujeitos aos valores corretos das variáveis explicativas.

Tais resultados e ordens de grandeza são compatíveis com resultados antes publicados - mas foram encontrados com técnicas econométricas alternativas e com uma base de dados significativamente revista (pelo IBGE em meados de 2007).

Finalmente, conquanto não se tenha discutido relações de causalidade neste trabalho, cumpre notar que tais conclusões são compatíveis com a hipótese de relaxamentos na política fiscal implicarem aumento da renda disponível do setor privado (e.g. reduções na carga tributária bruta e/ou aumentos nas transferências públicas de renda ao setor privado) têm significativo e rápido impacto sobre a dinâmica trimestral do consumo das famílias brasileiras.

\section{Referências bibliográficas}

ABE, R. H. Consumo no Brasil: quebras estruturais e suavização do consumo. Tese(Doutorado) - FGV/SP. Disponível em: <http://virtualbib.fgv.br/dspace/bitstream/handle/10438/4316/ Regis\%20Augusto\%20Hideshi\%20Abe.pdf? sequence=4>. Acesso em:05 abr. 2010.

BEECHEY, M.; HJALMARSSON, E.; OSTERHOLM, P. Testing the sxpectations hypothesis when interest rates are near integrated. Journal of Banking and Finance, v. 33, n. 5, p. $934-$ 943, 2009.

CAMPBELL, J. Y.; MANKIW, G. Consumption, income and interest rates: reinterpreting the time series evidence. In: OLIVIER, J. B.; FISCHER, S. (Org.). National Bureau of Economic Research Macroeconomics Annual. Cambridge, MA: MIT Press, 1989. p. 185-216.

CAVALCANTI, M. A. F. H. Um modelo macroeconométrico trimestral para o Brasil: possibilidades, limitações e resultados. Rio de Janeiro: IPEA, 2000. Mimeo.

et al. Principais características do modelo macroeconômico do IPEA. Rio de Janeiro: IPEA, 2002. Mimeo.

CEPAL. The reaction of the governments of the Americas to the international crisis: an overview of policy measures up to 31 December 2009. Santiago do Chile, 2010.

(36) Tais que o ajustamento ao equilíbrio nos modelos de correção de erros subjacentes é significativamente inferior a um ano. 
COMMANDEUR, J. J. F; KOOPMAN, S. J. An introduction to state space time series analysis. Oxford: Oxford University Press, 2007.

DICKEY, D. A; FULLER, W. A. Likelihood ratio statistics for autoregressive time series with a Unit Root. Econometrica, 49, p.1057-1079, 1981.

ENDERS, W. Applied econometric time series. 3rd. ed. New Jersey: Wiley, 2010.

ENGLE, R. F.; GRANGER, C. W. J. Co-integration e error correction: representation, estimation, and testing. Econometrica, v. 55, n. 2, p. 251-276, 1987.

FLAVIN, M. The adjustment of consumption to changing expectations about income. Journal of Political Economy, v. 89, n. 5, p. 974-1009, 1981.

FRANSES, P. H.; HALDRUP, N. The effects of additive outliers on tests for unit roots and cointegration. Journal of Business and Economic Statistics, v. 12, p. 471-478, 1994.

GOMES, F. A. R. Consumo no Brasil: teoria da renda permanente, formação de hábito e restrição à liquidez. Revista Brasileira de Economia, Rio de Janeiro, v. 58, n. 3, p. 381-402, 2004.

. Consumo no Brasil: comportamento otimizador, restrição de crédito ou miopia? Revista Brasileira de Economia, Rio de Janeiro, v. 64, n. 3, p. 261-275, 2010.

; FRANCHINI, D. S. The stationarity of consumption income ratios: evidence from South American countries. Economia Aplicada, v. 3, n. 4, p. 463-479, 2009.

; ISSLER, J. V.; SALVATO, M. A. Principais características do consumo de duráveis no Brasil e testes de separabilidade entre duráveis e não-duráveis. Revista Brasileira de Economia, v. 59, n. 1, p. 33-60, 2005.

; PAZ, L. S. Especificações para a função consumo: testes para países da América do Sul. Pesquisa e Planejamento Econômico, v. 34, n. 1, p. 39-56, 2004.

GRANGER, C. W. Empirical modeling in economics: specification and evaluation. Cambridge: Cambridge University Press, [1998].

GREGORY, A. W.; HANSEN, B. E. Residual-based tests for cointegration in models with regime shifts. Journal of Econometrics, v. 70, n. 1, p. 99-126, [1996].

HALL, R. E. Stochastic implications of the life cycle-permanent income hypothesis: theory and evidence. Journal of Political Economy, v. 86, n. 6, p. 971-987, [1978].

HAMILTON, J. D. Time series analysis. Princeton University Press, 1994.

HARRIS, R. I. D. Using cointegration analysis in econometric modelling. Essex: Prentice Hall, 1995.

HARVEY, A. C. Forecasting, structural time series models and the Kalman Filter. Cambridge: Cambridge University Press, 1989.

HJALMARSSON, E.; OSTERHOLM, P. A residual-based cointegration test for near unit root variables. Washington: Board of Governors of the Federal Reserve System. International Finance, 2007. (Discussion Papers, n. 907). 
HJALMARSSON, E.; OSTERHOLM, P. Testing for cointegration using the Johansen methodology when variables are near integrated: size distortions and partial remedies. A ser publicado em Empirical Economics, 2010.

IBGE. Contas Nacionais Trimestrais: Indicadores de Volume e Valores Correntes. Jul./Set. 2006. Coordenação de Contas Nacionais. Rio de Janeiro, 2006.

IBGE. Sistema de Contas Nacionais - Brasil 2003-2007. Coordenação de Contas Nacionais. Rio de Janeiro, 2009.

IBGE. Contas Nacionais Trimestrais: Indicadores de Volume e Valores Correntes - Nova Série Janeiro/Março 2010. Coordenação de Contas Nacionais. Rio de Janeiro, 2010.

ISSLER, J. V.; ROCHA, F. Consumo e restrição à liquidez e bem estar no Brasil. Revista de Economia Aplicada, v. 4, n. 4, p. 637-665, 2000.

JOHANSEN, S. Interpretation of cointegrating coefficients in cointegrated vector autoregressive model. Oxford Bulletin of Economics and Statistics, v. 67, n. 1, p. 93-104, 2005.

KROLZIG, H. M. Markov switching vector autoregressions. Modelling, statistical inferenceand application to business cycle analysis. Berlin: Springer-Verlag, 1997.

LEE, J; STRAZICICH, M. C. Minimum LM unit root test with two structural breaks. Review of Economics and Statistics, 63, p.1082-1089, 2003.

(2004). Minimum LM unit root test with one structural break. Appalachian State University (Working Paper). Disponível em: $<$ http://econ.appstate.edu/ RePEc/pdf/wp0417.pdf>. Acesso em: 10 abr. 2010.

LEYBOURNE, S.; NEWBOLD, P. Spurious rejections by cointegration tests induced by structural breaks. Applied Economics, 35, p. 1.117-1.121, 2003.

MUINHOS, M. K.; ALVES, S. A. L. (2003). Medium-size macroeconomic model for the Brazilian economy. (Working Paper Series, n. 64). Disponível em: < http://www.bcb.gov.br/ pec/wps/ingl/wps64.pdf>. Acesso em: 14 maio 2006.

PATTERSON, K. An introduction to applied econometrics: a time series approach. Palgrave Macmillan, 2000.

PAZ, L. S. Consumption in Brazil: myopia or liquidity constraints? A simple test using quarterly data. Applied Economic Letters, 12, p. 961-964, 2006.

; GOMES, F. A. R. (2008). Consumption in South America: myopia or liquidity constraints? (IBMEC Working Paper, n. 101). Disponível em: < http://www.insper.edu.br/ sites/default/files/2008_wpe156.pdf>. Acesso em: 10 abril 2010.

PERRON, P. The great crash, the oil price shock and the unit root hypothesis. Econometrica, v. 57, p. 1361-1401, 1989.

QUANTITATIVE MICRO SOFTWARE. E-Views 4 Users' Guide. Irvine, Califórnia, 2001. 
REIS, E. et al. Renda permanente e poupança precaucional: evidências empíricas para o Brasil no passado recente. Pesquisa e Planejamento Econômico, v. 28, n. 2, ago. 1998. . Model for projections and simulations of the Brazilian economy. IPEA, 1999. (Texto para Discussão, n. 619).

SANTOS, C. H. dos; MACEDO E SILVA, A. C; RIBEIRO, M. B. Uma metodologia de estimação da carga tributária líquida brasileira trimestral no período 1995-2009. Revista de Economia Contemporânea, v. 14, n. 2, p. 209-236, maio/ago. 2010.

; COSTA, F. R. Uma metodologia de estimação da carga tributária bruta brasileira em níveis trimestrais. Economia Aplicada, v. 12, n. 4, p. 581-606, 2008.

SHEA, J. Myopia, liquidity constraints, and aggregate consumption: a simple test. Journal of Money, Credit and Banking, 27, p. 798-805, 1995.

ZIVOT, E.; ANDREWS, D. W. K. Further evidence on the great crash, the oil price shock and the unit root hypothesis. Journal of Business and Economic Statistics, v. 10, p. 251-270, 1992. 
Novas evidências empíricas sobre a dinâmica trimestral do consumo agregado...

\section{Apêndice 1}

Tabela A1

Séries precisas utilizadas nas estimativas apresentadas neste texto

\begin{tabular}{|c|c|c|c|c|c|c|c|c|}
\hline & Consumo & $\begin{array}{c}\text { Consumo } \\
\text { c/ aj. } \\
\text { sazonal }\end{array}$ & PIB & $\begin{array}{c}\text { PIB } \\
\text { c/ aj. } \\
\text { sazonal }\end{array}$ & $\begin{array}{c}\text { Renda } \\
\text { disponível }\end{array}$ & $\begin{array}{c}\text { Renda } \\
\text { disponível } \\
\text { c/ aj. } \\
\text { sazonal }\end{array}$ & Juros & Crédito \\
\hline 1995:1 & 4,6058 & 4,6453 & 5,0558 & 5,1062 & 4,8648 & 4,9462 & 2,2033 & 3,00 \\
\hline 1995:2 & 4,6529 & 4,6822 & 5,1404 & 5,1469 & $\begin{array}{l}4,9040 \\
4,9472\end{array}$ & 4,9587 & 1,7300 & 2,73 \\
\hline $1995: 3$ & 4.7510 & 4.7066 & 5,1944 & 5.1543 & 5.0281 & 5.0051 & 2.2800 & 2.53 \\
\hline 1995:4 & 4,7880 & 4,7668 & 5,2866 & 5,2691 & 5,1270 & 5,0626 & 1,4367 & 2,30 \\
\hline 1996:1 & 4,6600 & 4,6991 & 5,1282 & 5,1801 & 4,8967 & 4.9797 & 1.4767 & 2.23 \\
\hline 1996:2 & 4.6862 & 4.7140 & 5.1810 & 5.1850 & 4.9735 & 4.9816 & 0.7967 & 2.17 \\
\hline 1996:3 & 4,7890 & 4,7439 & 5,2477 & 5,2082 & 5,0155 & 4,9940 & 1,3667 & 2,30 \\
\hline 1996:4 & 4,7935 & 4,7766 & 5.2156 & 5,2006 & 5,0924 & 5,0296 & 1,4567 & 2,60 \\
\hline 1997:1 & 4.7305 & 4.7680 & 5,1646 & 5,2168 & 4,9468 & 5,0308 & 0,9500 & 2,83 \\
\hline 1997:2 & 4,7530 & 4,7767 & 5,2293 & 5,2278 & 5,0164 & 5,0195 & 1,0067 & 3,03 \\
\hline 1997:3 & 4,8075 & 4,7629 & 5,2633 & 5,2280 & 5,0420 & 5,0220 & 1,5067 & 3,37 \\
\hline 1997:4 & 4.7629 & 4.7530 & 5.2491 & 5.2365 & 5.0680 & 5.0090 & 2.2833 & 3.70 \\
\hline 1998:1 & 4,7304 & 4,7637 & 5,1726 & 5,2228 & 4,9318 & 5,0149 & 1,8300 & 3,67 \\
\hline 1998:2 & 4,7405 & 4,7596 & 5,2438 & 5,2368 & 5,0411 & 5.0389 & 1,3933 & 3,70 \\
\hline 1998:3 & 4.8052 & 4.7628 & 5.2625 & 5.2322 & 5.0418 & 5.0232 & 2.1733 & 3.77 \\
\hline 1998:4 & 4,7487 & 4,7451 & 5,2294 & 5,2208 & 5,0582 & 5,0044 & 2,5800 & 3,70 \\
\hline 1999:1 & 4,7217 & 4,7507 & 5.1782 & 5.2230 & 4,8978 & 4.9788 & 1.6800 & 3,50 \\
\hline $1999: 2$ & 4,7397 & 4,7523 & 5,2361 & 5,2257 & 5,0123 & 5,0050 & 1,6633 & 3,43 \\
\hline $1999: 3$ & 4,7992 & 4,7632 & 5,2529 & 5,2291 & 4,9909 & 4,9737 & 0,9200 & 3,57 \\
\hline $1999: 4$ & 4,7790 & 4,7791 & 5.2516 & 5.2447 & 5.0479 & 4.9997 & 0.5433 & 3.63 \\
\hline $2000: 1$ & 4,7557 & 4,7798 & 5,2245 & 5,2633 & 4,9613 & 5,0393 & 1,1300 & 3,77 \\
\hline $2000: 2$ & 4,7878 & 4,7947 & 5,2744 & 5,2639 & 5,0113 & 5,0008 & 1,1733 & 4,20 \\
\hline $2000: 3$ & 4,8376 & 4,8098 & 5,2943 & 5,2746 & 5,0499 & 5,0331 & 0,2633 & 4,50 \\
\hline $2000: 4$ & 4,8166 & 4,8183 & 5,2946 & 5,2884 & 5,0684 & 5,0243 & 0,8867 & 4,97 \\
\hline 2001:1 & 4,7979 & 4,8164 & 5,2591 & 5,2936 & 4,9735 & 5,0495 & 0,7133 & 5,40 \\
\hline $2001: 2$ & 4,8193 & 4,8218 & 5,2974 & 5,2871 & 5,0173 & 5.0054 & 0,7633 & 5,67 \\
\hline $2001: 3$ & 4,8110 & 4,7920 & 5,2971 & 5,2805 & 5,0180 & 5,0006 & 0,7033 & 5,73 \\
\hline 2001:4 & 4,7985 & 4,8002 & 5,2876 & 5,2814 & 5,0669 & 5,0251 & 0,7067 & 5,87 \\
\hline $2002: 1$ & 4,8052 & 4,8182 & 5,2598 & 5,2921 & 4,9891 & 5.0643 & 0,8900 & 6,00 \\
\hline $2002: 2$ & 4,8395 & 4,8404 & 5,3158 & 5,3045 & 5,1088 & 5,0972 & 0,9300 & 6,10 \\
\hline $2002: 3$ & 4,8374 & 4,8252 & 5,3336 & 5,3194 & 5,0844 & 5,0653 & 0,6000 & 5,67 \\
\hline $2002: 4$ & 4,8207 & 4,8207 & 5,3355 & 5,3295 & 5,0854 & 5,0443 & $-0,5000$ & 5,17 \\
\hline $2003: 1$ & 4.8119 & 4.8212 & 5.2841 & 5.3155 & 4.9619 & 5.0382 & 0.1767 & 4.90 \\
\hline $2003: 2$ & 4,8081 & 4,8094 & 5,3254 & 5,3124 & 5,0550 & 5,0441 & 1,4233 & 5,23 \\
\hline $2003: 3$ & 4,8221 & 4,8147 & 5,3393 & 5,3270 & 5.1143 & 5,0925 & 1,4033 & 5,53 \\
\hline $2003: 4$ & 4,8297 & 4,8261 & 5,3421 & 5,3378 & 5,1493 & 5,1091 & 1,0667 & 5,67 \\
\hline $2004: 1$ & 4,8310 & 4,8397 & 5,3357 & 5,3654 & 5,0366 & 5,1138 & 0,6300 & 5,67 \\
\hline $2004: 2$ & 4,8471 & 4,8490 & 5,3978 & 5,3834 & 5.1544 & 5,1450 & 0,6833 & 5,80 \\
\hline 2004:3 & 4,8634 & 4,8587 & 5,3886 & 5.3780 & 5,1480 & 5,1226 & 0.6333 & 6.00 \\
\hline $2004: 4$ & 4,8798 & 4,8729 & 5,3910 & 5,3873 & 5,1789 & 5,1402 & 0,6500 & 6,53 \\
\hline $2005: 1$ & 4,8675 & 4,8770 & 5,3648 & 5,3928 & 5,0598 & 5,1378 & 0,7833 & 7,00 \\
\hline $2005: 2$ & 4.8887 & 4,8910 & 5.4271 & 5.4134 & 5.1555 & 5.1477 & 1.0533 & 7.57 \\
\hline $2005: 3$ & 4,9091 & 4,9054 & 5,4212 & 5,4104 & 5,1923 & 5,1623 & 1,3000 & 8,23 \\
\hline $2005: 4$ & 4,9303 & 4,9215 & 5,4243 & 5,4214 & 5.2230 & 5.1878 & 0,8667 & 8,67 \\
\hline 2006:1 & 4,9200 & 4,9306 & 5,4078 & 5,4345 & 5,1137 & 5,1909 & 0,8567 & 9.00 \\
\hline $2006: 2$ & 4,9406 & 4,9428 & 5,4464 & 5,4348 & 5,1947 & 5,1882 & 1,1467 & 9,27 \\
\hline $2006: 3$ & 4,9598 & 4,9554 & 5,4674 & 5,4544 & 5,2706 & 5,2363 & 1,0133 & 9,47 \\
\hline $2006: 4$ & 4.9781 & 4,9693 & 5,4711 & 5,4682 & 5.2738 & 5.2427 & 0.6600 & 9.67 \\
\hline 2007:1 & 4,9771 & 4,9888 & 5,4580 & 5,4860 & 5,2024 & 5,2790 & 0,5833 & 9,90 \\
\hline $2007: 2$ & 4,9964 & 4,9984 & 5,5085 & 5,4980 & 5,2789 & 5,2725 & 0,6900 & 10,40 \\
\hline $2007: 3$ & 5,0140 & 5,0080 & 5,5262 & 5,5105 & 5,3096 & 5,2716 & 0,6233 & 10,80 \\
\hline $2007: 4$ & 5,0463 & 5,0384 & 5,5359 & 5,5332 & 5,3116 & 5,2850 & 0,3967 & 11,17 \\
\hline $2008: 1$ & 5,0463 & 5,0592 & 5,5193 & 5,5495 & 5,2293 & 5,3047 & 0,3533 & 11,43 \\
\hline $2008: 2$ & 5,0739 & 5,0756 & 5,5712 & 5,5607 & 5,3436 & 5,3371 & 0,2200 & 11,77 \\
\hline $2008: 3$ & 5,1027 & 5,0948 & 5,5946 & 5,5765 & 5,3816 & 5,3411 & 0,7067 & 12,17 \\
\hline $2008: 4$ & 5,0839 & 5,0771 & 5,5441 & 5,5416 & 5,3484 & 5,3250 & 0,7433 & 12,47 \\
\hline $2009: 1$ & 5,0614 & 5.0753 & 5,4978 & 5,5296 & 5.2512 & 5,3260 & 0.5500 & 13,10 \\
\hline 2009:2 & 5,1034 & 5,1047 & 5,5547 & 5,5437 & 5,3511 & 5,3439 & 0,3533 & 13,87 \\
\hline $2009: 3$ & 5,1410 & 5,1321 & 5,5823 & 5,5636 & 5,4043 & 5,3633 & 0,5133 & 14,43 \\
\hline $2009: 4$ & 5,1580 & 5,1521 & 5,5860 & 5,5838 & 5,4079 & 5,3859 & 0,3400 & 14,80 \\
\hline
\end{tabular}

Economia e Sociedade, Campinas, v. 21, n. 3 (46), p. 607-641, dez. 2012. 


\section{Apêndice 2}

\section{Construindo séries a preços de 1995 a partir do deflator implícito trimestral do consumo das famílias}

A Tabela A2 mostra como foi construído o deflator implícito trimestral do consumo utilizado para deflacionar a proxy da renda disponível do setor privado utilizada neste trabalho (cujos valores nominais são apresentados no Apêndice 3). Os dados das colunas (1) e (3) foram extraídos das tabelas 1846 e 1620 das contas nacionais trimestrais do IBGE, respectivamente. Os dados das colunas (2) e (4) são autoexplicativos. Os dados da coluna (5) mostram a variação do índice de volume do trimestre corrente em relação à média verificada no ano anterior. O valor de 95,88 do índice de volume do primeiro trimestre de 1996, por exemplo, é -4,12\% inferior à média do índice de volume registrado no ano de 1995 (=100).

Os dados da coluna (6) foram calculados aplicando as variações reportadas na coluna (5) às médias anuais da coluna (2). O valor de R $\$ 135,96$ bilhões reportado no primeiro trimestre de 1997, por exemplo, é $0,35 \%$ menor do que os $\mathrm{R} \$ 136,43$ bilhões médios verificados em 1996.

Os dados da coluna (7) são calculados dividindo-se os dados da coluna (2) para o ano corrente pelos dados da mesma coluna para o ano anterior, multiplicados pela taxa de crescimento real anual implícita nos dados da coluna (4). O valor de 1,0415 reportado em 1998, por exemplo, é obtido, dividindo 157,50 (o valor médio reportado na Tabela 2 para $1998)$ por $151,2242(=152,32 *(1-0,0072))$. Note-se que 152,32 é o valor reportado na Tabela 2 para 1998 e $-0,72 \%$ é a taxa de crescimento anual implícita nos dados da Tabela (4) - uma vez que os índices médios de volume reportados para 1998 e 1997 nesta última tabela foram, respectivamente, 105,60 e 106,37.

Os dados da coluna (8) são obtidos utilizando-se os deflatores da coluna (7) para transformar os dados da coluna (6) para preços de 1995. O valor de 114,40 registrado no segundo trimestre de 1999 na Tabela (8), por exemplo, foi obtido, dividindo-se os R $\$ 154,86$ bilhões a preços de 1998 reportados na Tabela (6) por 1,3537 (=1,0415*1,0836*1,1995). Note-se que 1,1995, 1,0836 e 1,0145 são os valores reportados na coluna (7) para os deflatores anuais do consumo nos anos de 1996, 1997 e 1998, respectivamente.

Finalmente, os dados da coluna (9) são calculados dividindo-se os dados da coluna (1) pelos dados da coluna (8). 
Novas evidências empíricas sobre a dinâmica trimestral do consumo agregado...

Tabela A2

Metodologia de construção do deflator implícito trimestral do consumo

\begin{tabular}{|c|c|c|c|c|c|c|c|c|c|}
\hline & $\begin{array}{l}\text { Consumo } \\
\text { das } \\
\text { familias } \\
\text { (em } \\
\text { billhơes de } \\
\text { RS } \\
\text { correntes) } \\
\text { (1) }\end{array}$ & $\begin{array}{c}\text { Média } \\
\text { Anual } \\
\text { (dos } \\
\text { dados da } \\
\text { coluna 1) } \\
\text { (2) }\end{array}$ & $\begin{array}{l}\text { Despesa } \\
\text { de } \\
\text { consumo } \\
\text { das } \\
\text { familias } \\
\text { (em } \\
\text { volume) } \\
\text { (3) }\end{array}$ & $\begin{array}{c}\text { Média } \\
\text { Anual } \\
\text { (dos } \\
\text { dados da } \\
\text { coluna 3) } \\
\text { (4) }\end{array}$ & $\begin{array}{c}\text { Variaçăo } \\
\text { do } \\
\text { volume } \\
\text { contra a } \\
\text { média } \\
\text { ano } \\
\text { anterior } \\
\text { (5) }\end{array}$ & $\begin{array}{c}\text { Consumo } \\
\text { a preços } \\
\text { do ano } \\
\text { anterior }\end{array}$ & $\begin{array}{c}\text { Deflator } \\
\text { implicito } \\
\text { Anual }\end{array}$ & $\begin{array}{l}\text { Consumo } \\
\text { em RS } \\
\text { bilhồes } \\
\text { de } 1995\end{array}$ & $\begin{array}{l}\text { Deflator } \\
\text { trimestral } \\
\text { do } \\
\text { consumo } \\
(1) /(8)\end{array}$ \\
\hline $1995: 1$ & 100,06 & 110,18 & 101,45 & 100,00 & ND & ND & 1,0000 & 100,06 & 1 \\
\hline 1995:2 & 104,89 & 110,18 & 98,03 & 100,00 & ND & ND & 1,0000 & 104,89 & 1 \\
\hline 1995:3 & 115,70 & 110,18 & 101,3 & 100,00 & ND & ND & 1,0000 & 115,70 & 1 \\
\hline $1995: 4$ & 120,06 & 110,18 & 99,22 & 100,00 & ND & ND & 1,0000 & 120,06 & 1 \\
\hline $1996: 1$ & 120,12 & 136,43 & 95,88 & 103,24 & $-4,12 \%$ & 105,64 & 1,1995 & 105,64 & 1,1371 \\
\hline 1996:2 & 128,47 & 136,43 & 98,42 & 103,24 & $-1,58 \%$ & 108,44 & 1,1995 & 108,44 & 1,1848 \\
\hline 1996:3 & 146,75 & 136,43 & 109,08 & 103,24 & $9,08 \%$ & 120,18 & 1,1995 & 120,18 & 1,2210 \\
\hline $1996: 4$ & 150,40 & 136,43 & 109.57 & 103,24 & $9.57 \%$ & 120,72 & 1,1995 & 120,72 & 1.2458 \\
\hline 1997:1 & 142,19 & 152,32 & 102,88 & 106,37 & $-0,35 \%$ & 135,96 & $1,08.36$ & 113,35 & 1,2545 \\
\hline $1997: 2$ & 150,22 & 152,32 & 105,22 & 106,37 & $1,92 \%$ & 139,05 & 1,0836 & 115,93 & 1,2958 \\
\hline $1997: 3$ & 161,14 & 152,32 & 111,12 & 106,37 & $7,64 \%$ & 146,85 & 1,0836 & 122,43 & 1,3162 \\
\hline $1997: 4$ & 155,74 & 152,32 & 106,26 & 106,37 & $2.93 \%$ & 140,43 & 1,0836 & 117,08 & 1,3302 \\
\hline $1998: 1$ & 151,56 & 157,50 & 102,87 & 105,60 & $-3,29 \%$ & 147,31 & 1,0415 & 113,34 & 1,3372 \\
\hline 1998:2 & 155,39 & 157,50 & 103,91 & 105,60 & $-2,31 \%$ & 148,80 & 1,0415 & 114,49 & 1,3573 \\
\hline 1998:3 & 166,43 & 157,50 & 110,86 & 105,60 & $4.22 \%$ & 158,75 & 1,0415 & 122,14 & 1,3625 \\
\hline $1998: 4$ & 156,63 & 157,50 & 104,77 & 105,60 & $-1,50 \%$ & 150,03 & 1,0415 & 115,43 & 1,3569 \\
\hline 1999:1 & 159,89 & 172,34 & 101,98 & 106,00 & $-3,43 \%$ & 152,10 & 1,0513 & 112,36 & 1,4230 \\
\hline 1999:2 & 166,94 & 172,34 & 103,83 & 106,00 & $-1,68 \%$ & 154,86 & 1,0780 & & 1,4592 \\
\hline 1999:3 & 180,57 & 172,34 & 110,19 & 106,00 & $4,34 \%$ & 164,34 & 1,0988 & 121,41 & 1,4873 \\
\hline $1999: 4$ & 181,97 & 172,34 & 108 & 106,00 & $2,27 \%$ & 161,07 & 1,1297 & 118,99 & 1,5293 \\
\hline 2000:1 & 171,76 & 189,74 & 105,51 & 110,28 & $-0,46 \%$ & 171,55 & 1,0 & & 1,4776 \\
\hline $2000: 2$ & 187,03 & 189,74 & 108,95 & 110,28 & $2,78 \%$ & 177,14 & 1,0558 & 120,04 & 1,5581 \\
\hline $2000: 3$ & 200,00 & 189,74 & 114,51 & 110,28 & $8.03 \%$ & 186,18 & 1,0742 & 126,16 & 1,5852 \\
\hline $2000: 4$ & 200,16 & 189,74 & 112,14 & 110,28 & $5,79 \%$ & 182,33 & 1,0 & & 1,6201 \\
\hline 2001:1 & 199,39 & 206,62 & 110,05 & 111,03 & $-0,21 \%$ & 189,34 & 1,0531 & 121,25 & 1,6445 \\
\hline $2001: 2$ & 207,17 & 206,62 & 112,44 & 111,03 & $196 \%$ & 193,46 & 1,07099 & 123,88 & 1,6723 \\
\hline $2001: 3$ & 209,80 & 206,62 & 111,51 & 111,03 & $1,12 \%$ & 191 & 1,0935 & 122,86 & 1,7077 \\
\hline $2001: 4$ & 210,10 & 206,62 & 110,12 & 111,03 & $-0,14 \%$ & 189,46 & 1,1089 & 121,33 & 1,7318 \\
\hline $2002 ; 1$ & 214,45 & 228,01 & 110,86 & 113,17 & $=0,15 \%$ & 206,30 & 1,0395 & 122,14 & 1,7557 \\
\hline 2002:2 & 224,91 & 228,01 & 114,73 & 113,17 & 3,33 & 213 & & & 1,7793 \\
\hline $2002: 3$ & 232,58 & 228,01 & 114,49 & 113,17 & $3,12 \%$ & 213,06 & 1,0916 & 126,14 & 1,8438 \\
\hline $2002: 4$ & 240,12 & 228,01 & 112,59 & 113,17 & $1.41 \%$ & 200,52 & 1,1460 & 124,05 & 1,9356 \\
\hline 2003:1 & 256.9 & 263,19 & 111,61 & 112,29 & $-1,38 \%$ & 224,88 & & & 2,0892 \\
\hline $2003: 2$ & 259,49 & 263,19 & 111,18 & 112.29 & $-1,76 \%$ & 224,01 & 1,1584 & 122,50 & 2,1183 \\
\hline $2003: 3$ & 265,33 & 263,19 & 112,75 & 112,29 & $-0,37 \%$ & 227,17 & 1,1680 & 124,23 & 2,1358 \\
\hline 2003:4 & 271,03 & 263,19 & 113,61 & 112,29 & $0,39 \%$ & 228,91 & $1,1\}$ & 125,17 & 2,1653 \\
\hline 2004:1 & 272,14 & 290,15 & 113,76 & 116,58 & $1.31 \%$ & 266,64 & 1,0206 & 125,34 & 2,1712 \\
\hline $2004: 2$ & 281,98 & 290,15 & 115,6 & 116,58 & $2.95 \%$ & 270,95 & 1,0407 & 127,37 & 2,2139 \\
\hline $2004: 3$ & 296,93 & 290,15 & 7,5 & 116,58 & $4,64 \%$ & 275,41 & 1,0781 & 129,46 & 2,2937 \\
\hline $2004: 4$ & 309,57 & 290,15 & 119,45 & 116,58 & $6,38 \%$ & 279,98 & 1,1057 & 131,61 & 2,3523 \\
\hline $2005: 1$ & 308,06 & 323,56 & 117,99 & $121,7 \mathrm{x}$ & $1.21 \%$ & 293,67 & 1,0490 & 130,00 & 2,3697 \\
\hline $2005: 2$ & 319,83 & 323,56 & 120,51 & 121,78 & $3,37 \%$ & 299,94 & 1,0663 & 132,78 & 2,4059 \\
\hline $2005: 3$ & 327,44 & 323,56 & 123 & 121.78 & $5.51 \%$ & 306,14 & 1,0696 & 135,52 & 2,4161 \\
\hline $2005: 4$ & 338,90 & $32,3,56$ & 125,63 & 121,78 & $7,77 \%$ & 312,68 & 1,0838 & 138,42 & 2,4483 \\
\hline 2006:1 & 343,71 & 357,23 & 124,34 & 128,12 & $2,10 \%$ & 330,35 & 1,0404 & 137,00 & 2,5089 \\
\hline $2006: 2$ & 351,74 & 357,23 & 126,94 & 128,12 & $4,24 \%$ & 337,26 & 1,0429 & 139,86 & 2,5150 \\
\hline $2006: 3$ & 360,34 & 357,23 & 129,39 & 128,12 & $6.25 \%$ & 343,77 & 1,0482 & 142,56 & 2,5277 \\
\hline $2006: 4$ & 373,11 & 357,23 & 131,79 & 128,12 & $8.22 \%$ & 350,15 & 1,0656 & 145,20 & 2,5696 \\
\hline 2007:1 & 379,25 & & & & $2,77 \%$ & & 1,0331 & 145,06 & 2,6144 \\
\hline $2007: 2$ & 394.51 & 398,53 & 134,22 & 135,89 & $4.77 \%$ & 374,25 & 1,0541 & 147,88 & 2,6677 \\
\hline $2007: 3$ & 401,66 & 398,53 & 136.6 & 135,89 & $6.62 \%$ & 380,89 & 1,0545 & 150,50 & 2,6688 \\
\hline $2007: 4$ & 418.72 & 398.53 & 141,09 & 135,89 & $10.13 \%$ & 393,41 & 1,0643 & 155,45 & 2.6936 \\
\hline 2008:1 & 42752 & 453,12 & 141,09 & 145,47 & $3.82 \%$ & 413,78 & 1,0332 & 155,45 & 2.7502 \\
\hline $2008: 2$ & 448,84 & 453,12 & 145,03 & 145,47 & $6,72 \%$ & 425,33 & 1,0553 & 159,79 & 2,8088 \\
\hline $2008: 3$ & 468,76 & & 149,27 & 145,47 & $9,84 \%$ & 437,77 & 1,0708 & 164,46 & 2,8503 \\
\hline $2008: 4$ & 46734 & 453,12 & 146,49 & 145,47 & $7.80 \%$ & 429,61 & 1.0878 & 161,40 & 2,8956 \\
\hline 2009:1 & 455,62 & 493,11 & 143,23 & 151,37 & $-1,54 \%$ & 446,14 & 1,0212 & 157,81 & 2,8871 \\
\hline $2009: 2$ & & & 149,38 & 151,37 & $2.69 \%$ & 465,30 & 1,0487 & 164,58 & 2,9648 \\
\hline $2009: 3$ & 507.26 & 493,11 & 155,09 & 151,37 & $6.61 \%$ & 483,08 & 1,0500 & 170.88 & 2,9686 \\
\hline $2009: 4$ & 52159 & 493,11 & 157,76 & 151,37 & $8.45 \%$ & 491,40 & 1,0614 & 173,82 & 3,0007 \\
\hline
\end{tabular}

Fonte: Cálculos dos autores, a partir de dados de IBGE (2010). 


\section{Apêndice 3}

\section{Procedimentos de construção da proxy da renda disponível do setor privado utilizada neste texto}

A Tabela A3 mostra, de modo autoexplicativo, como a proxy para a renda disponível nominal trimestral do setor privado foi construída ${ }^{37}$. A metodologia de cálculo da renda nacional disponível segue a tabela 2205 das contas nacionais trimestrais. A série do PIB trimestral foi extraída da tabela 1846 das contas nacionais trimestrais. A estimativa da carga tributária líquida de transferências públicas foi construída pela coordenação de finanças públicas do IPEA, seguindo a metodologia proposta por Santos, Macedo e Silva e Ribeiro (2010). Os dados das colunas (2), (3) e (4) foram extraídos da tabela 2205 das contas nacionais trimestrais. A única qualificação importante a fazer é que - após a revisão das contas nacionais ocorrida em 2007 - esses últimos dados passaram a ser disponibilizados apenas a partir do ano 2000. Os dados das colunas (2), (3) e (4) para os anos de 1995 até 1999 foram, assim, extraídos da tabela 2205 divulgada pelo IBGE em dezembro de $2006^{38}$.

Tabela A3

Metodologia de Construção da proxy da renda disponível do setor privado utilizada neste texto (todos os dados em R\$ milhões correntes)

\begin{tabular}{|c|c|c|c|c|c|c|c|}
\hline & PIB & $\begin{array}{c}(+) \\
\text { Ordenados } \\
\text { e salários } \\
\text { (líquidos } \\
\text { recebidos } \\
\text { do exterior) } \\
(2)\end{array}$ & $\begin{array}{c}(+) \\
\text { Rendas de } \\
\text { propriedade } \\
\text { (líquidas } \\
\text { recebidas } \\
\text { do exterior) } \\
(3)\end{array}$ & $\begin{array}{c}(+) \text { Outras } \\
\text { transferências } \\
\text { correntes } \\
\text { (líquidas } \\
\text { recebidas do } \\
\text { exterior) } \\
\text { (4) }\end{array}$ & $\begin{array}{l}(=) \text { Renda } \\
\text { nacional } \\
\text { disponível } \\
\text { bruta }\end{array}$ & $\begin{array}{c}\text { (-) Carga } \\
\text { Tributária } \\
\text { Líquida de } \\
\text { Transfe- } \\
\text { rências } \\
\text { públicas } \\
\text { (6) }\end{array}$ & $\begin{array}{c}\text { (=) Proxy } \\
\text { nominal } \\
\text { da renda } \\
\text { disponível } \\
\text { do setor } \\
\text { privado } \\
\text { (7) }\end{array}$ \\
\hline 1995:1 & 156930 & -29 & -2214 & 722 & 155409 & 25760 & 129649 \\
\hline 1995:2 & 170781 & -27 & -3458 & 989 & 168285 & 27500 & 140785 \\
\hline 1995:3 & 180260 & -42 & -1549 & 853 & 179522 & 26880 & 152642 \\
\hline 1995:4 & 197670 & -46 & -2788 & 759 & 195595 & 27090 & 168505 \\
\hline 1996:1 & 185696 & -38 & -2238 & 796 & 184216 & 32020 & 152196 \\
\hline 1996:2 & 202822 & -25 & -3309 & 665 & 200153 & 28900 & 171253 \\
\hline 1996:3 & 216436 & -2 & -2434 & 545 & 214545 & 30520 & 184025 \\
\hline 1996:4 & 239011 & 3 & -4187 & 575 & 235402 & 32600 & 202802 \\
\hline 1997:1 & 213530 & 3 & -2442 & 575 & 211666 & 35130 & 176536 \\
\hline 1997:2 & 232515 & 6 & -4969 & 476 & 228028 & 32540 & 195488 \\
\hline 1997:3 & 240815 & 20 & -3395 & 480 & 237920 & 34190 & 203730 \\
\hline 1997:4 & 252287 & 21 & -6679 & 480 & 246109 & 34790 & 211319 \\
\hline 1998:1 & 228579 & 19 & -2722 & 398 & 226274 & 40910 & 185364 \\
\hline
\end{tabular}

(37) A série que aparece na Tabela A1 é a proxy nominal derivada na Tabela A3 transformada para R\$ bilhões e, depois, para preços de 1995 pelo deflator derivado na Tabela A2, dessazonalizada e logaritmizada (nesta ordem).

(38) Um procedimento que parece perfeitamente aceitável, tendo em vista que a revisão das contas nacionais não afetou a mensuração das variáveis das contas externas brasileiras. 
Novas evidências empíricas sobre a dinâmica trimestral do consumo agregado...

Tabela A3 - Continuação

\begin{tabular}{|c|c|c|c|c|c|c|c|}
\hline & PIB & $\begin{array}{c}(+) \\
\text { Ordenados } \\
\text { e salários } \\
\text { (líquidos } \\
\text { recebidos } \\
\text { do exterior) } \\
\text { (2) }\end{array}$ & $\begin{array}{c}(+) \\
\text { Rendas de } \\
\text { propriedade } \\
\text { (líquidas } \\
\text { recebidas } \\
\text { do exterior) } \\
(3)\end{array}$ & $\begin{array}{l}(+) \text { Outras } \\
\text { transferências } \\
\text { correntes } \\
\text { (líquidas } \\
\text { recebidas do } \\
\text { exterior) } \\
\text { (4) }\end{array}$ & $\begin{array}{c}(=) \text { Renda } \\
\text { nacional } \\
\text { disponível } \\
\text { bruta }\end{array}$ & $\begin{array}{c}\text { (-) Carga } \\
\text { Tributária } \\
\text { Líquida de } \\
\text { Transfe- } \\
\text { rências } \\
\text { públicas } \\
\text { (6) }\end{array}$ & $\begin{array}{c}\text { (=) Proxy } \\
\text { nominal } \\
\text { da renda } \\
\text { disponíve } \\
\text { do setor } \\
\text { privado } \\
\text { (7) }\end{array}$ \\
\hline 1998:2 & 249212 & 13 & -6228 & 371 & 243368 & 33480 & 209888 \\
\hline 1998:3 & 249543 & 28 & -5118 & 422 & 244875 & 34040 & 210835 \\
\hline 1998:4 & 251941 & 62 & -7296 & 470 & 245177 & 31750 & 213427 \\
\hline 1999:1 & 243152 & 144 & -7202 & 849 & 236943 & 46260 & 190683 \\
\hline 1999:2 & 266349 & 42 & -10166 & 702 & 256927 & 37680 & 219247 \\
\hline 1999:3 & 265252 & 38 & -6120 & 732 & 259902 & 41150 & 218752 \\
\hline 1999:4 & 290246 & 32 & -10874 & 744 & 280148 & 42050 & 238098 \\
\hline 2000:1 & 269648 & 46 & -5183 & 617 & 265129 & 54180 & 210949 \\
\hline $2000: 2$ & 291183 & 35 & -11411 & 697 & 280504 & 46640 & 233864 \\
\hline 2000:3 & 300681 & 23 & -5493 & 657 & 295868 & 48580 & 247288 \\
\hline 2000:4 & 317969 & 41 & -10647 & 818 & 308181 & 50730 & 257451 \\
\hline 2001:1 & 307319 & 64 & -9026 & 786 & 299144 & 61450 & 237694 \\
\hline $2001: 2$ & 324325 & 69 & -12323 & 891 & 312961 & 60440 & 252521 \\
\hline $2001: 3$ & 324245 & 60 & -9599 & 1034 & 315741 & 57690 & 258051 \\
\hline 2001:4 & 346247 & 27 & -14775 & 1155 & 332653 & 57850 & 274803 \\
\hline $2002: 1$ & 337948 & 10 & -8155 & 872 & 330675 & 72930 & 257745 \\
\hline $2002: 2$ & 370778 & 52 & -13948 & 1380 & 358263 & 63850 & 294413 \\
\hline 2002:3 & 372203 & 117 & -11355 & 2186 & 363151 & 65420 & 297731 \\
\hline $2002: 4$ & 396893 & 148 & -18807 & 2827 & 381061 & 68170 & 312891 \\
\hline 2003:1 & 391247 & 87 & -11905 & 2149 & 381578 & 83100 & 298478 \\
\hline 2003:2 & 419885 & 70 & -15680 & 1826 & 406102 & 73920 & 332182 \\
\hline 2003:3 & 429796 & 118 & -10166 & 2569 & 422317 & 66960 & 355357 \\
\hline $2003: 4$ & 459020 & 57 & -17723 & 2207 & 443560 & 70460 & 373100 \\
\hline 2004:1 & 438687 & 177 & -13173 & 2175 & 427866 & 93630 & 334236 \\
\hline 2004:2 & 483852 & 128 & -17222 & 2600 & 469356 & 85940 & 383416 \\
\hline 2004:3 & 495360 & 93 & -12192 & 2328 & 485589 & 90880 & 394709 \\
\hline $2004: 4$ & 523599 & 130 & -16421 & 2461 & 509769 & 92270 & 417499 \\
\hline $2005: 1$ & 494420 & 221 & -13936 & 2238 & 482942 & 109570 & 373372 \\
\hline $2005: 2$ & 535631 & 123 & -17764 & 2093 & 520084 & 102390 & 417694 \\
\hline 2005:3 & 542697 & 87 & -13852 & 2145 & 531078 & 96450 & 434628 \\
\hline $2005: 4$ & 574490 & 101 & -16566 & 2159 & 560184 & 106050 & 454134 \\
\hline 2006:1 & 549492 & 139 & -15108 & 2069 & 536591 & 119390 & 417201 \\
\hline 2006:2 & 579972 & 73 & -16536 & 2390 & 565900 & 112400 & 453500 \\
\hline $2006: 3$ & 602858 & 115 & -11737 & 2550 & 593786 & 102070 & 491716 \\
\hline 2006:4 & 637161 & 63 & -15593 & 2357 & 623987 & 122490 & 501497 \\
\hline 2007:1 & 621906 & 234 & -13871 & 2024 & 610293 & 135210 & 475083 \\
\hline $2007: 2$ & 664215 & 242 & -14317 & 1949 & 652089 & 128800 & 523289 \\
\hline $2007: 3$ & 672195 & 200 & -12762 & 1945 & 661578 & 121780 & 539798 \\
\hline $2007: 4$ & 703028 & 199 & -14734 & 1911 & 690403 & 144500 & 545903 \\
\hline 2008:1 & 693834 & 203 & -18363 & 1713 & 677387 & 164020 & 513367 \\
\hline $2008: 2$ & 753508 & 234 & -18448 & 1489 & 736783 & 148980 & 587803 \\
\hline 2008:3 & 779187 & 124 & -17403 & 1640 & 763548 & 144010 & 619538 \\
\hline 2008:4 & 778352 & 480 & -18601 & 3074 & 763304 & 154450 & 608854 \\
\hline 2009:1 & 717431 & 408 & -13633 & 1993 & 706198 & 155370 & 550828 \\
\hline 2009:2 & 778964 & 324 & -17729 & 1592 & 763151 & 138020 & 625131 \\
\hline 2009:3 & 797020 & 245 & -14416 & 1671 & 784520 & 124390 & 660130 \\
\hline 2009:4 & 849600 & 241 & -19518 & 1282 & 831605 & 161960 & 669645 \\
\hline
\end{tabular}

Fonte: Cálculos dos autores, a partir de dados de IBGE (2010) e IBGE (2006). 